\title{
Effects of High-Volume versus High-Load Resistance Training on Skeletal Muscle Growth and Molecular Adaptations
}

Christopher G. Vann ${ }^{1,2}$, Casey L. Sexton ${ }^{1}$, Shelby C. Osburn ${ }^{1}$, Morgan A. Smith ${ }^{1}$, Cody T. Haun $^{3}$, Melissa N. Rumbley ${ }^{1}$, Petey W. Mumford ${ }^{4}$, Brian K. Ferguson ${ }^{1}$, Nathan T. Montgomery ${ }^{1}$, Carlton D. Fox ${ }^{1}$, Bradley A. Ruple ${ }^{1}$, James McKendry ${ }^{5}$, Jonathan Mcleod ${ }^{5}$, Adil Bashir ${ }^{6}$, Ronald J. Beyers ${ }^{6}$, Matthew S. Brook ${ }^{7}$, Kenneth Smith ${ }^{7}$, Philip J Atherton ${ }^{7}$, Darren T. Beck ${ }^{1,8}$, James R. McDonald $^{1}$, Kaelin C. Young ${ }^{1,8}$, Stuart M. Phillips ${ }^{5}$, Michael D. Roberts ${ }^{1,8^{*}}$

Affiliations: ${ }^{1}$ School of Kinesiology, Auburn University, Auburn AL, USA, ${ }^{2}$ Duke Molecular Physiology Institute, Duke University School of Medicine, Duke University, Durham, NC, USA; ${ }^{3}$ Fitomics, LLC, Pelham, AL, USA, ${ }^{4}$ Department of Kinesiology, Lindenwood University, St. Charles MO, USA, ${ }^{5}$ Department of Kinesiology, McMaster University, Hamilton ON, CAN; ${ }^{6}$ MRI Research Center, Auburn University, Auburn AL, USA; ${ }^{7}$ MRC-ARUK Centre of Excellence for Musculoskeletal Ageing Research, Clinical, Metabolic, and Molecular Physiology, University of Nottingham, Derby, UK; ${ }^{8}$ Edward Via College of Osteopathic Medicine - Auburn Campus, Auburn AL, USA

*address correspondence to:

Michael D. Roberts, Ph. D.

Associate Professor, School of Kinesiology

Director, Molecular and Applied Sciences Laboratory

Affiliate Research Professor, Edward Via College of Osteopathic Medicine - Auburn Campus Auburn University

301 Wire Road, Office 286

Auburn, AL 36849

Phone: $334-844-1925$

Fax: $334-844-1467$

E-mail: mdr0024@auburn.edu

Running title: Higher volume versus higher load training adaptations 


\section{ABSTRACT}

Aim: We evaluated the effects of higher-load (HL) versus (lower-load) higher-volume (HV) resistance training on skeletal muscle hypertrophy, strength, and muscle-level molecular markers. Methods: Trained men $(n=15$, age: $23 \pm 3$ y; training experience: $7 \pm 3$ y) performed unilateral lower body training for 6 weeks ( $3 \mathrm{x}$ weekly), where single legs were assigned to HV and HL paradigms. Vastus lateralis (VL) biopsies were obtained prior to study initiation (PRE) as well as 3 days (POST) and 10 days following the last bout (POSTPR). Body composition and strength tests were performed at each testing session, and biochemical assays were performed on muscle tissue after study completion. Two-way within subjects repeated measures ANOVAs were performed on all dependent variables except tracer data, which was compared using dependent samples t-tests. Results: A significant $(\mathrm{p}<0.05)$ interaction existed for unilateral leg

44 extension 1RM (HV $<\mathrm{HL}$ at POST and POSTPR). Six-week integrated sarcoplasmic protein 45 synthesis (iSarcoPS) rates were higher in the HV versus HL leg, while no difference between

46 legs existed for integrated myofibrillar protein synthesis rates. Main time effects existed for

47 unilateral leg press strength (PRE<POST and POSTPR), knee extensor peak torque (PRE and POST<POSTPR), dual-energy $\mathrm{x}$-ray absorptiometry (DXA)-derived upper leg lean mass

49 (PRE<POST and POSTPR), ultrasound-derived VL thickness (PRE and POSTPR $<$ POST), 50 sarcoplasmic protein concentrations (POST and POSTPR $<\mathrm{PRE}$ ), and tropomyosin and troponin

51 protein abundances (POST and POSTPR $<\mathrm{PRE}$ ). Conclusions: With the exception of

52 differences in leg extensor strength and iSarcoPS between legs, our data suggest that short-term

53 (6 weeks) HV and HL training elicit similar hypertrophic, strength, and molecular-level 54 adaptations. 
bioRxiv preprint doi: https://doi.org/10.1101/2021.07.01.450728; this version posted July 1, 2021. The copyright holder for this preprint (which was not certified by peer review) is the author/funder, who has granted bioRxiv a license to display the preprint in perpetuity. It is made available under aCC-BY 4.0 International license.

55 Keywords: Higher-load resistance training; higher-volume resistance training; muscle

56 hypertrophy; sarcoplasmic protein; myofibrillar protein 


\section{1. INTRODUCTION}

58 Skeletal muscle hypertrophy has been defined as an increase in the weight or cross-

59 sectional area of muscle ${ }^{1,2}$, with the increased volume of muscle coming from an enlargement of

60 each muscle fiber ${ }^{3-5}$. It is generally recognized that resistance training results in skeletal muscle

61 growth through proportional increases in myofibrillar and sarcoplasmic protein content ${ }^{6-9}$.

62 Myofibril proteins are defined herein as the proteins that make up the rigid structure of muscle

63 (e.g., dystrophin, actinin, titin, nebulin, etc.) as well as contractile proteins (e.g., actin and

64 myosin isoforms). In contrast, sarcoplasmic proteins are involved with signal transduction,

65 energy synthesis, energy breakdown, and other metabolic processes ${ }^{10}$.

Recently, there has been interest regarding whether or not higher-load (HL) versus

67 higher-volume (HV) resistance training elicits differential training adaptations at the

68 macroscopic, molecular, and functional levels. Historically, research has typically suggested that

69 HL training elicits superior increases in strength and muscle fiber hypertrophy compared to

70 lower-load HV training ${ }^{11}$. However, Mitchell and colleagues reported that 10 weeks of HL or

71 HV resistance training led to similar increases in muscle hypertrophy as assessed through MRI

72 and fiber histology ${ }^{12}$. Subsequent literature indicates that both HL and HV training can: i) elicit

73 similar changes in skeletal muscle hypertrophy (assessed through either ultrasound or MRI) ${ }^{13-17}$,

74 and ii) elicit similar strength adaptations ${ }^{13,18}$, although equivocal evidence exists suggesting HL

75 training elicits superior strength adaptations ${ }^{14,15,17}$. Reasons for similar outcomes between HL

76 and $\mathrm{HV}$ training could be due to total volume lifted being comparable between paradigms.

77 However, few HV versus HL studies have sought to modulate training loads with the intent of

78 accumulating more training volume during HV conditions. 
Our laboratory recently reported that six weeks of extremely HV resistance training

80 decreased the relative abundance of myosin heavy chain and actin protein content per milligram

81 of dry tissue ${ }^{19}$. Our findings, as well as those of others who have reported moderate-to-higher

82 volume resistance training elicits similar molecular adaptations ${ }^{20-22}$, led us to postulate that a

83 disproportionate increase in the sarcoplasmic space relative to myofibril protein accretion may be

84 a training adaptation to $\mathrm{HV}$ resistance training ${ }^{23}$. More recently, our laboratory demonstrated

85 that lower volume, higher load resistance training (3-5 sets of 2-6 repetitions at 65-90\% 1RM)

86 resulted in a maintenance of type I muscle fiber cross-sectional area (fCSA) while increasing

87 type II fCSA. Additionally, no changes in sarcoplasmic protein concentrations were observed

88 despite a modest but significant decrease in actin protein concentrations ${ }^{24,25}$. While preliminary,

89 these two studies from our laboratory suggest that HV resistance training may facilitate a more

90 robust expansion of non-contractile proteins in myofibers, whereas HL training may promote a

91 proportional increase in myofibril protein accretion with muscle growth. However, no single

92 study to date has examined whether HV versus HL training elicit differential molecular

93 adaptations related to the aforementioned findings.

94 The purpose of the present study was to elucidate whether six weeks of unilateral HV

95 versus HL lower-body resistance training differentially affected metrics of skeletal muscle

96 hypertrophy, strength, and/or molecular variables assessed from skeletal muscle biopsies

97 sampled from the vastus lateralis (VL). The intent of our study was to ensure HV training

98 achieved more training volume relative to HL training. We hypothesized no differences would

99 exist between $\mathrm{HV}$ and HL training when examining changes in VL muscle area assessed via

100 magnetic resonance imaging (MRI), or VL thickness assessed via ultrasound. Additionally, we

101 hypothesized that HL training would elicit superior increases in various indices of strength. 
However, we posited HV training would result in increased sarcoplasmic protein concentrations and a concomitant decrease in the relative abundances of contractile proteins, whereas HL

104 training would result in no changes in these markers. Additionally, we hypothesized that the 105 integrated sarcoplasmic protein synthesis (iSarcoPS) rates would be greater in HV versus HL 106 training, whereas integrated myofibrillar protein synthesis (iMyoPS) rates would be greater in 107 HL versus HV training.

\section{RESULTS}

\section{$110 \quad 2.1 \quad$ Participant characteristics}

Baseline participant characteristics can be found in Table 1. Briefly, 15 college-age males ( $23 \pm 3$ years) with an average training age of $7 \pm 3$ years volunteered for this study. At

113 PRE, participants weighed $89.5 \pm 11.6 \mathrm{~kg}$ with $69.1 \pm 7.4 \mathrm{~kg}$ being lean soft tissue mass (LSTM) 114 and $17.3 \pm 7.5 \mathrm{~kg}$ being fat mass, on average. Additionally, participants had an average relative 115 squat to body mass ratio of $1.9 \times$ body mass $(167 \pm 34 \mathrm{~kg})$.

\section{$117 \quad 2.2 \quad$ Training Volume and Strength Metrics}

119 participants is presented for unilateral leg press and unilateral leg extension one repetition 120 maximums (1RM) due to one participant feeling lower extremity discomfort at POST with these 121 exercises.

122 There was a condition $\times$ time interaction observed for lower body training volume $123\left(p<0.001, \eta_{\mathrm{p}}{ }^{2}=0.914\right.$; Fig. 1a). Additionally, there was a main effect of condition $(p=0.003$, $\left.124 \eta_{\mathrm{p}}{ }^{2}=0.467\right)$ where the HV condition completed more volume than the HL condition $(8100 \pm 480$ 
$125 \mathrm{~kg}$ versus $7296 \pm 421 \mathrm{~kg}$, respectively). Lower body training volume changed over time $126\left(p<0.001, \eta_{\mathrm{p}}^{2}=0.955\right.$, Fig. 1a) and within each condition over time $\left(\mathrm{HV}: p<0.001, \eta_{\mathrm{p}}{ }^{2}=0.952\right.$;

127 HL: $p<0.001, \eta_{\mathrm{p}}{ }^{2}=0.954$, Fig. 1a). Post hoc analysis revealed lower training volumes at weeks 1 128 and 2 in the HV leg compared to the HL leg $(p<0.001)$, no differences between conditions at 129 week 3, and higher training volumes in the HV leg at weeks 4-6 as compared to the HL leg $130 \quad(\mathrm{p}<0.001)$

A condition $\times$ time interaction $\left(p=0.512, \eta_{\mathrm{p}}{ }^{2}=0.050\right.$, Fig. 1b) was not observed for estimated unilateral leg press 1RM. Additionally, no main effect of condition ( $p=0.475$, $\eta_{\mathrm{p}}{ }^{2}=0.040$, Fig. $\left.1 \mathrm{~b}\right)$ was observed. There was a main effect of time $\left(p<0.001, \eta_{\mathrm{p}}{ }^{2}=0.818\right.$, Fig. 1b) where estimated unilateral leg press 1RM at POST $(p<0.001)$ and POSTPR $(p<0.001)$ were greater than PRE. A condition $\times$ time interaction was observed for estimated unilateral leg extension $1 \mathrm{RM}\left(p=0.032, \eta_{\mathrm{P}}^{2}=0.265\right.$, Fig. 1c). A main effect of condition $\left(p=0.026, \eta_{\mathrm{p}}{ }^{2}=0.328\right.$,

137 Fig. 1c) was also observed where the HL condition (grand mean $=113 \pm 5 \mathrm{~kg}$ ) estimated unilateral 138 leg extension 1RM was higher than the HV condition (grand mean=109 $\pm 5 \mathrm{~kg}$ ). Estimated 139 unilateral leg extension 1RM also changed over time $\left(p<0.001, \eta_{\mathrm{p}}{ }^{2}=0.885\right.$, Fig. 1c) and within 140 each condition over time (HV: $\left.p<0.001, \eta_{\mathrm{p}}{ }^{2}=0.858 ; \mathrm{HL}: p<0.001, \eta_{\mathrm{p}}{ }^{2}=0.884\right)$. Post hoc analysis 141 revealed no differences in estimated unilateral leg extension 1RM at PRE; however, the HL 142 condition had higher values at POST and POSTPR compared to the HV condition $(\mathrm{p}<0.05)$. There was no conditionxtime interaction observed for knee-extensor peak torque at $14460^{\circ} / \mathrm{sec}\left(p=0.995, \eta_{\mathrm{p}}{ }^{2}<0.001\right.$, Fig. $\left.1 \mathrm{~d}\right)$ and $120^{\circ}\left(p=0.366, \eta_{\mathrm{p}}{ }^{2=} 0.069\right.$, Fig. 1e $)$, or knee-extensor 145 mean torque at $120^{\circ} / \mathrm{sec}\left(p=0.681, \eta_{\mathrm{p}}{ }^{2}=0.027\right.$, Fig. $\left.1 \mathrm{~g}\right)$. Additionally, there were no main effects

146 of condition or time observed for the aforementioned variables. Knee-extensor mean torque at $14760 \%$ sec changed over time $\left(p=0.041, \eta_{\mathrm{p}}{ }^{2}=0.204\right.$, Fig. 1f) where knee-extensor mean torque at 
$60 \%$ sec was higher at POSTPR than at PRE $(p=0.029)$ and POST $(p=0.043)$. There were no

149 differences observed between PRE and POST ( $p=0.805)$.

\subsection{Body Composition}

154 (DXA) scans. Total body mass increased over time $\left(p<0.001, \eta_{\mathrm{p}}{ }^{2}=0.435\right)$, where POST $155(p=0.001)$ and POSTPR $(p=0.012)$ body masses were greater than PRE. However, no 156 differences were observed between POST and POSTPR body masses $(p=0.119)$. Lean soft tissue 157 mass $\left(\right.$ LSTM) increased over time $\left(p=0.003, \eta_{\mathrm{p}}{ }^{2}=0.338\right)$ where POST LSTM was greater than PRE $(p=0.002)$ and POSTPR $(p=0.014)$. No significant differences in LSTM were observed 159 between PRE and POSTPR ( $p=0.286)$. No differences were observed for DXA measured whole body fat mass $(p=0.097)$.

\subsection{Segmental Upper Leg Composition}

There were no condition $\times$ time interactions observed for DXA-derived upper leg mass $(p=$

$1640.069, \eta_{\mathrm{p}}{ }^{2}=0.173$, Fig. 2a), upper leg $\operatorname{LSTM}\left(p=0.174, \eta_{\mathrm{p}}{ }^{2}=0.117\right.$, Fig. $\left.2 \mathrm{~b}\right)$, or upper leg fat mass

$165\left(p=0.959, \eta_{\mathrm{p}}{ }^{2}=0.003\right.$, Fig. $\left.2 \mathrm{c}\right) . \quad$ A main effect of time was observed for upper leg mass $(p=0.001$,

$166 \eta_{\mathrm{p}}{ }^{2}=0.392$, Fig. $\left.2 \mathrm{a}\right)$ where POST $(p=0.002)$ and POSTPR $(p=0.013)$ were higher than PRE. No

167 differences were observed between POST and POSTPR $(p=0.240)$. A main effect of time was

168 observed for DXA upper leg LSTM $\left(p=0.001, \eta_{\mathrm{p}}{ }^{2}=0.418\right.$, Fig. $\left.2 \mathrm{~b}\right)$ where POST $(p<0.001)$ and 169 POSTPR $(p=0.002)$ were higher than PRE. No differences were observed between POST and 
POSTPR $(p=0.148)$. No main effects of condition $(p=0.102)$ or time $(p=0.595)$ were observed

171 for DXA upper leg fat mass.

\subsection{Vastus Lateralis Muscle Morphology}

A condition $\times$ time interaction was observed for magnetic resonance image (MRI)-derived

175

176

177

178

179

180

\subsection{Muscle Protein Adaptations}

and POSTPR $(p=0.003)$. No differences were observed between PRE and POSTPR $(p=0.614)$.

There were no interactions observed for muscle pennation angle of the VL $\left(p=0.393, \eta_{\mathrm{p}}{ }^{2}=0.064\right.$, Fig. 3f) or estimated VL muscle fiber length $\left(p=0.602, \eta_{\mathrm{p}}{ }^{2}=0.036\right.$, Fig. $\left.3 \mathrm{c}\right)$. Additionally, there were no main effects of condition or time for the aforementioned variables $(p>0.05)$.

\section{***INSERT FIGURE 3***}

There was no condition $\times$ time interaction observed for sarcoplasmic protein concentrations per $\mathrm{mg}$ of wet tissue weight $\left(p=0.112, \eta_{\mathrm{p}}{ }^{2}=0.159\right.$, Fig. $\left.4 \mathrm{a}\right)$. There was a main effect of condition $\left(p=0.002, \eta_{\mathrm{p}}{ }^{2}=0.497\right.$, Fig. $\left.4 \mathrm{a}\right)$ where sarcoplasmic protein concentrations in the HV group were higher than the HL group (44.8 \pm 1.6 versus $42.6 \pm 1.3$ respectively). Additionally, there was a main effect of time $\left(p=0.022, \eta_{\mathrm{p}}{ }^{2}=0.239\right.$, Fig. 4a) where PRE sarcoplasmic protein concentrations were higher than POST $(p=0.038)$ and $\operatorname{POSTPR}(p=0.032)$. 
No differences in sarcoplasmic protein concentrations were observed between POST and

$194 \operatorname{POSTPR}(p=0.524)$

There were no conditionxtime interactions observed for myosin heavy chain (MyHC)

196 protein abundance per $\mathrm{mg}$ of wet tissue weight $\left(p=0.668, \eta_{\mathrm{p}}{ }^{2}=0.028\right.$, Fig. $\left.4 \mathrm{~b}\right)$ or actin protein

197 abundance per $\mathrm{mg}$ of wet tissue weight $\left(p=0.254, \eta_{\mathrm{p}}{ }^{2}=0.093\right.$, Fig. $\left.4 \mathrm{c}\right)$. Additionally, no main

198 effects of condition or time were observed for these variables $(p>0.05)$. There was no

199 condition $\times$ time interaction $\left(p=0.180, \eta_{\mathrm{p}}{ }^{2}=0.115\right.$, Fig. $\left.4 \mathrm{~d}\right)$ or main effect of condition $(p=0.762$,

$200 \eta_{\mathrm{p}}{ }^{2}=0.007$, Fig. 4d) observed for tropomyosin protein abundance per mg wet tissue weight.

201 However, a main effect of time was observed for this variable $\left(p=0.008, \eta_{\mathrm{p}}{ }^{2}=0.294\right.$, Fig. $\left.4 \mathrm{~d}\right)$

202 where PRE was greater than POST $(p=0.009)$ and POSTPR $(p=0.010)$. No differences were

203 observed between POST and POSTPR $(p=0.704)$. There was no condition $\times$ time interaction

$204\left(p=0.112, \eta_{\mathrm{p}}{ }^{2}=0.145\right.$, Fig. $\left.4 \mathrm{e}\right)$ or a main effect of condition $\left(p=0.912, \eta_{\mathrm{p}}{ }^{2}=0.001\right.$, Fig. $\left.4 \mathrm{e}\right)$

205 observed for troponin protein abundance per mg wet tissue weight. A main effect of time was

206 observed for this variable $\left(p<0.001, \eta_{\mathrm{p}}{ }^{2}=0.431\right.$, Fig. 4e) where PRE was greater than POST

$207(p<0.001)$ and POSTPR $(p=0.005)$. No differences were observed between POST and POSTPR

$208(p=0.867)$.

209

***INSERT FIGURE 4***

2102.7 Six-week Integrated Myofibrillar and Sarcoplasmic Protein Synthesis

211 No difference was observed in integrated myofibrillar protein synthesis (iMyoPS)

212 between the HV and HL conditions ( $p=0.687 ; d=-0.106$; Figure 5a). A significant difference was

213 observed for integrated sarcoplasmic protein synthesis (iSarcoPS) where the HV condition

214 exhibited a higher iSarcoPS (\%/day) than the HL condition ( $p=0.0018 ; d=0.693$; Figure 5b). 


\section{DISCUSSION}

Chief findings from the current study include: i) a condition $\times$ time interaction for MRI-

218 derived VL mCSA although, when the model was statistically decomposed, no differences were

219 found between conditions or over time, ii) an interaction for estimated unilateral leg extension

$2201 \mathrm{RM}$ where values were higher in the HL condition at POST and POSTPR when compared to

221 the HV condition at the same time points, and iii) no significant difference in iMyoPS rates,

222 albeit iSarcoPS was greater in the HV versus HL condition over the duration of the study. The

223 relevance of these as well as other findings are discussed below.

The literature regarding macro-level muscle tissue changes following high- and low-load

training are sparse. Furthermore, limitations in the available literature exist due to lack of congruency between loading paradigms and discrepancies on what constitutes low-load/high-

227 volume and high-load/low-volume training. Nonetheless, there is prior literature that has

228 interrogated differences between such training paradigms. Holm and colleagues ${ }^{26}$ reported that 229 high-load ( 70\% 1RM) versus very low-load ( 15.5\% 1RM) leg extensor training increased

230 quadriceps CSA; however, the change in the high-load condition was greater than the change in

231 the low-load condition. Chestnut and Docherty ${ }^{27}$ reported similar increases in muscle CSA of

232 the upper arm following 10 weeks of upper body resistance training using $~ 85 \%$ of $1 \mathrm{RM}$ for 6

233 sets of 4 repetitions versus $\sim 70 \%$ for 3 sets of 10 repetitions. The aforementioned study by

234 Mitchell and colleagues reported that performing three sets of knee-extensor training to fatigue at

$23530 \%$ or $80 \%$ of $1 \mathrm{RM}$ resulted in similar increases in quadriceps volume measured by MRI. Both

236 modalities yielded greater quadriceps hypertrophy than performing one set at $80 \% 1 \mathrm{RM}$ to

237 voluntary failure ${ }^{12}$. Furthermore, a systematic review and meta-analysis conducted by

238 Schoenfeld and colleagues concluded that similar skeletal muscle growth can be realized across a 
239 variety of loading ranges ${ }^{28}$. As mentioned previously, while we observed a condition $\times$ time

240 interaction for VL mCSA, decomposition of the model yielded no significant differences

241 between HL and HV training. This is in agreement with previous literature showing that (on

242 average), when loading exceeds 30\% 1RM and training is executed near or at volitional fatigue,

243 similar increases in whole-muscle hypertrophy can be realized.

244 Unilateral leg press and leg extension strength metrics increased over time, albeit there

245 was no interaction observed for leg extensor peak torque or leg press strength changes. However,

246 an interaction was observed for leg extension strength changes, where values increased more in

247 the HL versus HV condition. Several studies have examined changes in strength between

248 different loading paradigms. Campos and colleagues reported high-load resistance training (3-

$2495 \mathrm{RM}$ ) over an 8-week period yielded greater leg extension strength increases compared to high-

250 volume resistance training $(20-28 \mathrm{RM}){ }^{29}$; however, no differences in strength adaptations were

251 reported between the 3-5RM group and a third group which performed training using 9-11RM

252 loads. Additionally, Jenkins et al. published two studies comparing 30\% 1RM versus 80\% 1RM

253 leg extensor training ${ }^{14,15}$. Results from both studies suggest that higher-load training elicited

254 greater strength increases due to neural factors. Jessee and colleagues ${ }^{30}$ reported that unilateral

255 training (4 sets to volitional failure) over an 8-week period resulted in greater strength

256 adaptations for HL training (70\% 1RM/no blood flow restriction) than low load conditions with

257 or without blood flow restriction. Furthermore, Schoenfeld and colleagues reported increased

258 barbell back squat strength with lower (30-50\% 1RM) and higher-load (70-80\% 1RM) training,

259 with higher-load training resulting in greater strength adaptations ${ }^{17}$. When considering our

260 findings in the context of these studies, it seems plausible that training at $60-90 \%$ 1RM over

261 shorter-term periods may elicit similar strength changes. Collectively, our findings in the 
context of prior literature suggest that, while training at 30\% 1RM seemingly yields similar

263 increases in hypertrophy compared to training at higher loads, 30\% 1RM training may not

264 optimize strength gains due to differential neural adaptations.

A novel aspect of the current study was to compare how HL versus HV training affected molecular markers from muscle biopsies. This interrogation was prompted by select literature

267 suggesting that a disproportionate increase in non-contractile proteins in myofibers may occur

268 following high-volume resistance training. However, as reviewed by Jorgenson and colleagues,

269 it should be noted that a large portion of the literature has shown that mechanical-load induced

270 skeletal muscle hypertrophy is largely attributed to proportional increases in the contractile and

271 non-contractile elements of the myofiber ${ }^{31}$. Nonetheless, a handful of studies exist showing that

272 a disproportionate increase in non-contractile proteins may occur following months to years of

273 resistance training ${ }^{20,21,32,33}$. Recently, our laboratory has reported increases in sarcoplasmic

274 protein concentrations with concomitant decreases in the relative abundances of myosin heavy

275 chain and actin protein abundances per mg of dry tissue weight following 6 weeks of extremely

276 high-volume resistance training in previously-trained college-aged men ${ }^{19}$. We concluded at the

277 time that "sarcoplasmic hypertrophy" may have occurred and that both of these molecular

278 observations were reflective of this phenomenon. Our laboratory subsequently reported that

279 sarcoplasmic protein concentrations were maintained while minor decrements occurred in actin

280 protein abundance in previously-trained college-aged males that partook in a 10-week low-

281 volume, high-load training paradigm ${ }^{24}$. When considering the findings from both studies, we

282 hypothesized that HV training might facilitate sarcoplasmic hypertrophy, whereas HL training

283 may facilitate proportional accretion of contractile and sarcoplasmic proteins with whole-muscle

284 hypertrophy (i.e., conventional hypertrophy). In the current study, we observed decreased 
sarcoplasmic protein concentrations for both conditions at POST. Additionally, no significant

286 changes in the relative abundances of actin and myosin heavy chain proteins were observed in

287 either condition. Although these data disagree with prior findings from Haun et al., it is

288 important to note the key differences that exist between the high-volume components of each

289 study. First, Haun et al. utilized a bilateral exercise paradigm using the barbell back squat as the

290 primary knee-extensor exercise, whereas the current study was a unilateral study design using a

291 combination of unilateral leg press and leg extension to overload the knee-extensor muscles. To

292 this end, it could be posited that training stress on the legs was much greater in the Haun et al.

293 study versus the current study. Second, Haun et al. used a 6-week intervention starting at 10 sets

294 of 10 repetitions per week (for each exercise) and finishing with 32 sets of 10 repetitions per

295 week where loads were standardized at $60 \% 1 \mathrm{RM}^{34}$. The current study started the HV leg at 10

296 sets of 10 repetitions per week (split between two exercises) at week 1 and finished with 20 sets

297 of 10 repetitions per week at week 6 where loads were standardized at $60 \% 1 \mathrm{RM}$. Thus,

298 although the HV leg was exposed to more training volume compared to the HL leg herein, the

299 HV leg did not experience nearly the amount of volume as both legs incurred in the study by

300 Haun et al. Moreover, the total training volume data in Figure 1 indicates that the HV leg was

301 only exposed to $\sim 11 \%$ more volume compared to the HL leg. We speculate that similar

302 molecular adaptations between legs may have been due a relatively small difference in total

303 training volume between legs throughout the duration of the study. Alternatively stated, a higher

304 total training volume may have been needed to yield data suggestive of sarcoplasmic versus

305 myofibrillar expansion in the HV condition. In spite of our null findings, however, it is

306 intriguing that $\mathrm{HV}$ training increased iSarcoPS versus HL training. This partially supports the 
notion that $\mathrm{HV}$ training may affect the sarcoplasmic protein pool to a greater extent than $\mathrm{HL}$ training, but this warrants continued research.

As with many studies examining the effects of training interventions, the present study is

310 limited due to a small sample size. The procurement of skeletal muscle tissue via percutaneous

311 muscle biopsy inherently has a finite tissue yield. Due to this limitation, we lacked sufficient

312 tissue to perform histology and assess fCSA values in each leg over time, and these assays would

313 have been greatly beneficial for this study. While protein synthesis rates were measured herein,

314 it is notable that muscle protein breakdown rates were not assessed and could have influenced

315 outcomes. Additionally, previous literature has shown the ability to measure gross changes in

316 skeletal muscle growth after 3-6 weeks of resistance training in untrained to recreationally

317 trained men ${ }^{34-36}$. In this regard, we posit that the training status of the cohort in the current study

318 may have precluded our ability to detect any meaningful training adaptations over the 6-week

319 training period.

320 In conclusion, similar changes in muscle volume, morphology, and protein composition

321 appeared with 6 weeks of HV versus HL training. However, HL training resulted in a greater

322 increase in leg extension strength and higher 6-week iSarcoPS rates. Additionally, the current

323 data challenge our prior muscle-molecular findings given: i) the lack of change in sarcoplasmic

324 protein concentrations observed in the HV condition, and ii) no alterations being observed in 325 myosin heavy chain and actin protein abundances following training. However, the current 326 iSarcoPS findings suggest some muscle-molecular differences exist between HV and HL 327 training, and warrant further research. 


\subsection{Ethical approval and Pre-screening}

Prior to study initiation, this protocol was reviewed and approved by the Auburn

332 University Institutional Review Board and was conducted in accordance to the standards set by

333 the latest revision of the Declaration of Helsinki (IRB approval \#: 19-245 MR 1907). hypertension), or any conditions that preclude the collection of a skeletal muscle biopsy. Additionally, training status for participants was determined by two criteria: i) self-reported bodyweight (estimated from a 3 repetition maximum [3RM] test) in accordance to standards

342 screening visit, participants were asked to maintain their current nutritional practices and to cease 343 all training outside of the study.

\section{$345 \quad 4.2 \quad$ Study design}

A schematic of the study design is provided in Figure 6a. Briefly, participants performed

347 a battery of testing prior to the start of training (PRE), 72 hours following the last bout of

348 training after 6 weeks of unilateral lower body resistance training (POST), and 10 days following

349 the last bout of training (POSTPR). The battery of tests performed are detailed further below,

350 following a description of the training intervention and tracer methodologies. 
354 leg leg press and single-leg leg extension) 3 days per week in conjunction with compound upper

355 body exercises (i.e., barbell bench press, pronated grip barbell row, barbell stiff-leg deadlift).

356 Notably, participants were randomly assigned to lower body training conditions prior to the start

357 of the study, where some participants performed HV training on the left leg and HL training on

358 the right leg or vice versa. All upper body exercises were performed for 3 sets of 10 repetitions

359 at $70 \%$ of tested 1RM. Progression for the lower body training can be found in Figure $6 \mathrm{~b}$.

\section{$361 \quad 4.4 \quad$ Isotope Tracer Protocol} provided to the participants three days prior to and over the first 6 weeks of the study at $1{\mathrm{~mL} \cdot \mathrm{kg}^{-}}^{-}$

$364{ }^{1}$ of lean body mass. For rapid enrichment of deuterium $\left({ }^{2} \mathrm{H}\right)$ participants were instructed to 365 orally consume 6 doses of $\mathrm{D}_{2} \mathrm{O}$ over an eight-hour period, three days prior to the first data 366 collection (PRE), and were instructed to consume a top-up dose daily thereafter consisting of one

367 dose of $\mathrm{D}_{2} \mathrm{O}$ until data collection was performed at the conclusion of week 6 of the study 368 (POST). Saliva samples were taken utilizing sterile salivettes (SARSTEDT AG \&Co, Nümbrect, 369 Germany). Briefly, participants were instructed to chew on the cotton swab for 1 min and place 370 the swab back into the top compartment of the salivette. This process was completed daily for 371 the first 10 days of the study and every Monday, Wednesday, and Friday thereafter. Participants 372 were instructed to place salivettes in their home freezers on days when saliva was donated 373 outside of the laboratory. Samples were stored at $-20 \square$ until further processing as described 374 below. 


\subsection{Testing sessions}

Urine specific gravity testing for adequate hydration. Upon arrival to each testing session

378 participants submitted a urine sample $(\sim 5 \mathrm{~mL})$ for urine specific gravity (USG) assessment.

379 Measurements were performed using a handheld refractometer (ATAGO; Bellevue, WA, USA).

380 USG levels in all participants were $\leq 1.020$ indicative of a euhydrated state ${ }^{38}$ and thus were

381 considered adequately hydrated for further testing.

Body composition testing. Following hydration testing, participants underwent height

mass collected to the nearest $0.1 \mathrm{~kg}$ and height to the nearest $0.5 \mathrm{~cm}$. Participants were then

subjected to a full body dual energy x-ray absorptiometry (DXA) scan (Lunar Prodigy; GE coefficient (ICC) of 0.998 for total body lean mass. 
Estimated fiber length was calculated using methods similar to those described by Fukunaga and

400 colleagues ${ }^{40}$.

$$
\text { est. fiber length }=\frac{a}{\operatorname{Cos}\left(90^{\circ}-\theta\right)}
$$

401 Whereas a is equal to the distance between the superficial fascia and the deep aponeurosis and $\theta$

402 is equal to the angle of pennation. Importantly - to minimize variability in measurements as

403 suggested in previous studies ${ }^{41,42}$ - all measures were taken by the same investigator (S.C.O.)

404 whom in a test-retest validation on 11 participants has been found to have an ICC of 0.983.

405 Critically, this investigator was not privy to the (HV or HL) condition for each image.

406 Moreover, the location of measurements were marked, using anatomical landmarks, by the

407 investigator so that the subsequent MRI scans and muscle biopsies could be obtained from the

408 same plane of measurement.

MRI for muscle cross-sectional area. Following ultrasound assessments, participants

410 were shuttled to the Auburn University MRI Research Center to perform dual- leg mid-thigh

411 MRI scans. All measurements were performed on a 3T VARIO system (Siemens, Erlangen,

412 Germany). Briefly, upon arrival participants were placed in a supine position for 10 minutes to

413 allow for body fluid stabilization to occur. Volume coil was used for RF transmit and body and

414 spine array coils placed around the legs were used for signal receive. 3D gradient echo sequence

415 (3D fast low angle shot) was used to acquire fat suppressed images with the following

416 parameters: $\mathrm{TR} / \mathrm{TE}=10 / 4.92 \mathrm{~ms}$; flip angle $=10^{\circ} ;$ bandwidth $=510 \mathrm{~Hz} /$ pixel, in-plane

417 resolution $1 \mathrm{~mm} \times 1 \mathrm{~mm}$ and slice thickness $=2.2 \mathrm{~mm}$. An axial $3 \mathrm{D} 35.2 \mathrm{~mm}$ thick slab (a6

418 partitions) was placed to image both thighs with the thickness dimension carefully centered on

419 the participant biopsy marking. Following the conclusion of the study, MRI scans were digitized

420 offline using Osirix MD software (Pixmeo, Geneva, CHE), and software tools were used to 
manually trace the border of the VL yielding mCSA values. All MRI scans and image analyses were performed by the same investigators (R.J.B. and M.A.S., respectively), without knowledge of the (HV or HL) condition. were collected using a 5-gauge needle under local anesthesia as previously described ${ }^{43,44}$.

426 Immediately following tissue procurement, tissue was teased of blood and connective tissue,

427 wrapped in pre-labelled foils, flash frozen in liquid nitrogen, and subsequently stored at $-80^{\circ} \mathrm{C}$

428 for molecular analyses described below.

Strength Testing. Following muscle skeletal muscle biopsies, participants underwent

431 leg extensor peak torque and 3RM testing. For right and left leg extensor peak torque testing, 432 participants were fastened to the isokinetic dynamometer. Each participant's lateral epicondyle

433 was aligned with the axis of the dynamometer, and seat height was adjusted to ensure the hip

434 angle was approximately $90^{\circ}$. Prior to torque assessment, each participant performed a warm-up 435 consisting of submaximal to maximal isokinetic knee extensions. Participants then completed 436 five maximal voluntary isokinetic knee extension actions at $1.05 \mathrm{rad} / \mathrm{s}\left(60^{\circ} / \mathrm{s}\right)$ and $2.09 \mathrm{rad} / \mathrm{s}$ $437\left(120^{\circ} / \mathrm{s}\right)$. Participants were provided verbal encouragement during each contraction. The 438 isokinetic contraction resulting in the greatest value was used for analyses. Following isokinetic 439 dynamometry participants performed maximum strength testing for the exercises utilized over 440 the duration of the study (single-leg leg press, single-leg leg extension, barbell bench press, 441 pronated grip barbell row, and barbell stiff-leg deadlift). Briefly, participants performed 3 warm442 up sets starting at $\sim 50 \%$ of their self-selected opening weight for 10 repetitions, then $75 \%$ of 443 their self-selected opening weight for 5 repetitions, and $90 \%$ of their self-selected opening 
444 weight for 3 repetitions. Following warm-ups, participants executed their opening attempt for 3

445 repetitions with $5-10 \%$ increases being made from there on until a 3RM was achieved. All

446 strength testing was performed by investigators holding the NSCA certified strength and

447 conditioning specialist credential (C.G.V. and C.L.S.). This process was completed for all 448 exercises at PRE while only the single-leg exercises were tested at POST and POSTPR.

\subsection{Biochemical assays}

452 performed using the proteomic validated "MIST" or "myofibrillar isolation and solubilization

453 technique" ${ }^{45}$. $1.7 \mathrm{~mL}$ polypropylene tubes were pre-filled with ice-cold buffer $(300 \mu \mathrm{L}$; Buffer

454 1: $25 \mathrm{mM}$ Tris, $\mathrm{pH} 7.2,0.5 \%$ Triton $\mathrm{X} \square 100$, protease inhibitors) and placed on ice. Skeletal

455 muscle foils were removed from $-80^{\circ} \mathrm{C}$, placed on a liquid nitrogen-cooled ceramic mortar and

456 pestle, and tissue was pulverized into $2-4 \mathrm{~mm}^{3}$ chunks. Chunks $(\sim 20 \mathrm{mg})$ were weighed using a 457 scale with a sensitivity of $0.0001 \mathrm{~g}$ (Mettler-Toledo; Columbus, OH, USA) and placed into 1.7

$458 \mathrm{~mL}$ polypropylene tubes with buffer and placed on ice. Samples were homogenized using tight-

459 fitting pestles and centrifuged at $1,500 \mathrm{~g}$ for 10 minutes at $4{ }^{\circ} \mathrm{C}$. Supernatants (sarcoplasmic

460 fraction) were collected and placed in new $1.7 \mathrm{~mL}$ polypropylene tubes on ice. As a wash step,

461 the resultant myofibrillar pellet was resuspended in $300 \mu \mathrm{L}$ of Buffer 1 and centrifuged at 1,500

$462 \mathrm{~g}$ for 10 minutes at $4^{\circ} \mathrm{C}$. The supernatant was discarded and the myofibrillar pellet was 463 solubilized in $300 \mu \mathrm{L}$ of ice-cold resuspension buffer $(20 \mathrm{mM}$ Tris- $\mathrm{HCl}, \mathrm{pH}$ 7.2, $100 \mathrm{mM} \mathrm{KCl}$, $46420 \%$ glycerol, $1 \mathrm{mM}$ DTT, $50 \mathrm{mM}$ spermidine, protease inhibitors). Protein concentrations for 465 the sarcoplasmic fraction were determined the same day as protein isolations to minimize freeze466 thaw artifact, and the myofibrillar fraction was prepared for actin and myosin heavy chain 
467 protein abundance analyses and stored at $-80^{\circ} \mathrm{C}$ until analysis occurred. The methodologies used

468 for the above are described in further detail below.

Determination of sarcoplasmic protein concentrations. Sarcoplasmic protein

470 resuspensions were batch-assayed for determination of protein concentration using a

471 commercially available bicinchoninic acid (BCA) kit (Thermo Fisher Scientific; Waltham, MA,

472 USA). Samples were assayed in duplicate (sarcoplasmic protein) using a microplate assay

473 protocol where a small volume of sample was assayed $(20 \mu \mathrm{L}$ of $5 \mathrm{x}$ diluted sample $+200 \mu \mathrm{L}$

474 Reagent $\mathrm{A}+\mathrm{B})$. The average duplicate coefficient of variation for sarcoplasmic protein

475 concentration was $2.27 \%$.

SDS-PAGE and Coomassie staining for relative contractile protein abundance.

477 Determination of contractile protein abundances per mg wet tissue were performed as previously

478 described by our laboratory and others ${ }^{19,44,46,47}$. Briefly, SDS-PAGE sample preps were made

479 using $10 \mu \mathrm{L}$ resuspended myofibrils, $65 \mu \mathrm{L}$ distilled water (diH2O), and $25 \mu \mathrm{L} 4 \times$ Laemmli

480 buffer. Samples (5 $\mu \mathrm{L})$ were then loaded on precast gradients (4-15\%) SDS-polyacrylamide gels

481 in duplicate (Bio-Rad Laboratories) and subjected to electrophoresis at $180 \mathrm{~V}$ for 40 minutes

482 using pre-made 1x SDS-PAGE running buffer (Ameresco). Following electrophoresis, gels were

483 rinsed in diH2O for 15 minutes and immersed in Coomassie stain (LabSafe GEL Blue; G-

484 Biosciences; St. Louis, MO, USA) for 2 hours. Gels were then destained in diH2O for 60

485 minutes, and band densitometry was performed with a gel documentation system and associated

486 software (ChemiDoc; Bio-Rad Laboratories, Hercules, CA, USA). Given that a standardized

487 volume from all samples was loaded onto gels, myosin heavy chain and actin band densities

488 were normalized to input muscle weights to derive arbitrary density units (ADU) per mg wet

489 muscle. All values were then divided by the mean of the PRE time point to depict myosin heavy 
490 chain, actin, tropomyosin, and troponin abundances. Our laboratory has reported that this

491 method yields exceptional sensitivity in detecting 5-25\% increases in actin and myosin content

492 44. Average duplicate coefficients of variation for relative actin, myosin, tropomyosin, and

493 troponin protein concentrations herein were $1.95 \%, 1.90 \%, 2.22 \%$, and $3.54 \%$ respectively.

494 Six-week integrated myofibrillar and sarcoplasmic protein synthesis rates. Protein

495 isolations were performed using 30 mg of tissue utilizing the MIST method as described above.

496 Prior to preparation for tracer analysis the sarcoplasmic protein fraction was lyophilized and

497 precipitated in $1 \mathrm{~mL}$ of $1 \mathrm{M}$ perchloric acid to form a pellet. The myofibrillar pellet was purified

498 by adding $500 \mu \mathrm{L}$ of $\mathrm{DDH}_{2} \mathrm{O}$ followed by vortexing for $5 \mathrm{~s}$ and centrifugation at $1500 \mathrm{rpm}$ at $4 \square$

499 for 10 minutes. Following centrifugation, $1 \mathrm{~mL}$ of $0.3 \mathrm{M} \mathrm{NaOH}$ was added to the sample and

500 then vortexed for $5 \mathrm{~s}$ followed by being placed in a heat block at $50 \square$ for 30 minutes of which

501 samples were vortexed for 5 s every 10 minutes. Samples then underwent centrifugation at

$50210,000 \mathrm{rpm}$ at $4 \square$ for 10 minutes. The supernatant (sarcoplasmic or myofibrillar fraction) was

503 transferred into a $4 \mathrm{~mL}$ glass screw-top tube. $1 \mathrm{M}$ perchloric acid was then added to tubes and

504 centrifuged at $2500 \mathrm{rpm}$ at $4 \square$ for 10 minutes. The supernatant was removed, and the remaining

505 pellet was washed in $70 \%$ ethanol and centrifuged at $2500 \mathrm{rpm}$ at $4 \square$ for 10 minutes twice.

506 Amino acids were extricated through the addition of $1 \mathrm{~mL}$ of 1 Dowex resin (50WX8-200 resin;

507 Sigma Aldrich) and $1 \mathrm{~mL}$ of $1 \mathrm{M} \mathrm{HCl}$ prior to heating at $110 \square$ for 72 hours. Cation exchange

508 columns were used to isolate the free amino acids after which the amino acids were analyzed for

509 deuterated-alanine content $\left({ }^{2} \mathrm{H}\right.$-alanine $)$ using a gas chromatography pyrolysis isotope ratio mass

510 spectrometer. The amino acids were derivatized as their $n \square$ methoxycarbonyl methyl esters.

511 Dried samples were suspended in $60 \mu \mathrm{l}$ distilled water and $32 \mu \mathrm{l}$ methanol, and following vortex,

$51210 \mu \mathrm{l}$ of pyridine and $8 \mu \mathrm{l}$ of methylchloroformate were added. Samples were vortexed for $30 \mathrm{~s}$ 
513 and left to react at room temperature for $5 \mathrm{~min}$. The newly formed $n \square$ methoxycarbonyl methyl

514 esters of amino acids were then extracted into $100 \mu \mathrm{l}$ of chloroform. A molecular sieve was

515 added to each sample for $20 \mathrm{~s}$ before being transferred to a clean glass Gas Chromatography

516 insert. Incorporation of deuterium into protein bound alanine was determined by gas

517 chromatography-pyrolysis-isotope ratio mass spectrometry (Delta V Advantage) alongside a

518 standard curve of known $1 \square$ alanine $\square 2,3,3,3 \square \mathrm{d} 4$ enrichment to validate measurement accuracy

519 of the instrument ${ }^{48}$.

520 The water phase of saliva was injected 6 times with the average of the last 3 injections

521 being used for data analysis. The ${ }^{2} \mathrm{H}$ isotope enrichments for both muscle and saliva were

522 initially expressed as $\delta^{2} \mathrm{H} \%$ and then converted to atom percent excess using standard equations

523 as reported by Wilkinson et al ${ }^{48}$. Fractional synthetic rate for the myofibrillar and sarcoplasmic

524 protein fractions were calculated using the standard precursor-product method as described by 525 other laboratories ${ }^{49-51}$.

$$
\operatorname{FSR}\left(\% d a y^{-1}\right)=\left[\frac{\left(E_{A l a 2}-E_{A l a 1}\right)}{E_{B W} \times t}\right] \times 3.7 \times 100
$$

526 Whereas $\mathrm{E}_{\mathrm{Ala} 1}$ and $\mathrm{E}_{\mathrm{Ala} 2}$ represent ${ }^{2} \mathrm{H}$ enrichment at PRE and POST respectively (in atom percent

527 excess) from skeletal muscle biopsies. $\mathrm{E}_{\mathrm{BW}}$ is the average ${ }^{2} \mathrm{H}$ enrichment (in atom percent

528 excess) of total body water between time-points and $t$ is time in the number of days $\mathrm{D}_{2} \mathrm{O}$ was

529 ingested. Multiplying by 3.7 adjusts for average ${ }^{2} \mathrm{H}$ atoms that can be bound to alanine and 530 multiplying by 100 converts this to a percentage per day ${ }^{48,52}$.

$532 \quad 4.7 \quad$ Statistical Analyses

533 Statistical analyses were performed using SPSS (Version 26; IBM SPSS Statistics

534 Software, Chicago, IL, USA), open-source software JASP (Version 0.11.0; JASP Team; 2019), 
and RStudio (Version 1.1.463, R Foundation for Statistical Computing, Vienna, AT). Prior to

536 analysis, assumptions testing for normality was performed using Shapiro-Wilk's test for all

537 dependent variables. If the assumption of heteroscedasticity was violated for repeated measures,

538 a Greenhouse-Geisser correction factor was applied. Dependent variables were analyzed using

539 multi-factorial repeated measures ANOVAs, and LSD post hoc tests were used to assess

540 differences in dependent variables for leg or time. Statistical significance for null hypothesis

541 testing was set at $p<0.05$. Data are presented throughout as mean \pm standard deviation (bar

542 graphs) or box and whiskers plots including median (central horizontal line), $25^{\text {th }}$ and $75^{\text {th }}$

543 percentile (box), minimum and maximum values (vertical lines) and mean values (cross).

\section{AUTHOR CONTRIBUTIONS}

547 CGV and MDR designed the study and primarily drafted the manuscript. PWM and CGV ran

548 statistical analyses. CGV designed the training program and coordinated the study. All other

549 authors assisted with testing, assays, or other aspects of the studies.

\section{CONFLICTS OF INTEREST}

552 None of the authors declares conflicts of interest exist in relation to these data.

\section{SUPPORT}

$555 \quad$ Funding for assays and participant compensation was provided through discretionary

556 laboratory funds from M.D.R. Funding for MRI imaging was provided through discretionary

557 laboratory funds from K.C.Y. Funding for deuterium oxide was provided through discretionary 
558 lab funds from S.M.P. Additionally, a portion of C.G. Vann's effort was funded through the

559 National Institutes of Health (R01AG054840). The data that support the findings of this study

560 are available from the corresponding author upon reasonable request.

561

562 ACKNOWLEDGEMENTS

563 The authors would like to thank the participants for their dedication to executing this

564 study. We would also like to thank Johnathon Moore, Samantha Slaughter, Andy Cao, Max

565 Coleman, Max Michel, Megan Edwards, and Sullivan Clement for their assistance in collecting 566 data. 


\section{REFERENCES}

568 1. Tesch PA, Larsson L. Muscle hypertrophy in bodybuilders. Eur J Appl Physiol Occup Physiol. 1982;49(3):301-306.

2. Folland JP, Williams AG. The adaptations to strength training : morphological and

3. Goldberg AL, Etlinger JD, Goldspink DF, Jablecki C. Mechanism of work-induced glycogen changes in human muscle fibers. J Appl Physiol. 1972;33(4):421-425.

5. Morpurgo B. Ueber Activitiits-Hypertrophie der willktirlichen Muskeln. Arch path Anat Physiol. 1897;1S0:522-554.

6. Goldspink G. The combined effects of exercise and reduced food intake on skeletal muscle fibers. J Cell Comp Physiol. 1964;63:209-216.

7. Gordon EE, Kowalski K, Fritts M. Adaptations of muscle to various exercises. Studies in rats. Jama. 1967;199(2):103-108.

8. Helander EA. Influence of exercise and restricted activity on the protein composition of skeletal muscle. Biochem J. 1961;78(3):478-482.

9. Seiden D. Quantitative analysis of muscle cell changes in compensatory hypertrophy and work-induced hypertrophy. Am J Anat. 1976;145(4):459-465.

10. Haun CT, Vann CG, Roberts BM, Vigotsky AD, Schoenfeld BJ, Roberts MD. A Critical Evaluation of the Biological Construct Skeletal Muscle Hypertrophy: Size Matters but So Does the Measurement. Front Physiol. 2019;10:247.

11. Fry AC. The role of resistance exercise intensity on muscle fibre adaptations. Sports Med. 2004;34(10):663-679.

12. Mitchell CJ, Churchward-Venne TA, West DW, et al. Resistance exercise load does not determine training-mediated hypertrophic gains in young men. J Appl Physiol (1985). 2012;113(1):71-77.

13. Ikezoe T, Kobayashi T, Nakamura M, Ichihashi N. Effects of low-load, higher-repetition versus high-load, lower-repetition resistance training not performed to failure on muscle strength, mass, and echo intensity in healthy young men: a time-course study. J Strength Cond Res. 2017.

14. Jenkins ND, Housh TJ, Buckner SL, et al. Neuromuscular Adaptations After 2 and 4 Weeks of $80 \%$ Versus $30 \% 1$ Repetition Maximum Resistance Training to Failure. $J$ Strength Cond Res. 2016;30(8):2174-2185.

15. Jenkins NDM, Miramonti AA, Hill EC, et al. Greater Neural Adaptations following High- vs. Low-Load Resistance Training. Front Physiol. 2017;8:331.

16. Morton RW, Oikawa SY, Wavell CG, et al. Neither load nor systemic hormones determine resistance training-mediated hypertrophy or strength gains in resistance-trained young men. J Appl Physiol (1985). 2016;121(1):129-138.

17. Schoenfeld BJ, Peterson MD, Ogborn D, Contreras B, Sonmez GT. Effects of Low- vs. High-Load Resistance Training on Muscle Strength and Hypertrophy in Well-Trained Men. J Strength Cond Res. 2015;29(10):2954-2963.

18. Dinyer TK, Byrd MT, Garver MJ, et al. Low-Load vs. High-Load Resistance Training to Failure on One Repetition Maximum Strength and Body Composition in Untrained Women. J Strength Cond Res. 2019;33(7):1737-1744. 
19. Haun CT, Vann CG, Osburn SC, et al. Muscle fiber hypertrophy in response to 6 weeks of high-volume resistance training in trained young men is largely attributed to sarcoplasmic hypertrophy. PLoS One. 2019;14(6):e0215267.

20. MacDougall JD, Sale DG, Elder GC, Sutton JR. Muscle ultrastructural characteristics of elite powerlifters and bodybuilders. Eur J Appl Physiol Occup Physiol. 1982;48(1):117126.

21. Meijer JP, Jaspers RT, Rittweger J, et al. Single muscle fibre contractile properties differ between body-builders, power athletes and control subjects. Exp Physiol. 2015;100(11):1331-1341.

22. Roth SM, Martel GF, Ivey FM, et al. Ultrastructural muscle damage in young vs. older men after high-volume, heavy-resistance strength training. J Appl Physiol (1985). 1999;86(6):1833-1840.

23. Roberts MD, Haun CT, Vann CG, Osburn SC, Young KC. Sarcoplasmic Hypertrophy in Skeletal Muscle: A Scientific "Unicorn" or Resistance Training Adaptation? Front Physiol. 2020;11:816.

24. Vann CG, Osburn SC, Mumford PW, et al. Skeletal Muscle Protein Composition Adaptations to 10 Weeks of High-Load Resistance Training in Previously-Trained Males. Front Physiol. 2020;11:259.

25. Vann CG, Osburn SC, Mumford PW, et al. Skeletal Muscle Protein Composition Adaptations to 10 Weeks of High-Load Resistance Training in Previously-Trained Males. Frontiers in Physiology. 2020;11(259).

26. Holm L, Reitelseder S, Pedersen TG, et al. Changes in muscle size and MHC composition in response to resistance exercise with heavy and light loading intensity. $J$ Appl Physiol (1985). 2008;105(5):1454-1461.

27. CHESTNUT JL, DOCHERTY D. The Effects of 4 and 10 Repetition Maximum WeightTraining Protocols on Neuromuscular Adaptations in Untrained Men. The Journal of Strength \& Conditioning Research. 1999;13(4):353-359.

28. Schoenfeld BJ, Grgic J, Ogborn D, Krieger JW. Strength and Hypertrophy Adaptations Between Low- vs. High-Load Resistance Training: A Systematic Review and Metaanalysis. J Strength Cond Res. 2017;31(12):3508-3523.

29. Campos GE, Luecke TJ, Wendeln HK, et al. Muscular adaptations in response to three different resistance-training regimens: specificity of repetition maximum training zones. Eur J Appl Physiol. 2002;88(1-2):50-60.

30. Jessee MB, Buckner SL, Mouser JG, et al. Muscle Adaptations to High-Load Training and Very Low-Load Training With and Without Blood Flow Restriction. Front Physiol. 2018;9:1448.

31. Jorgenson KW, Phillips SM, Hornberger TA. Identifying the Structural Adaptations that Drive the Mechanical Load-Induced Growth of Skeletal Muscle: A Scoping Review. Cells. 2020;9(7):1658.

32. Penman KA. Ultrastructural changes in human striated muscle using three methods of training. Res Q. 1969;40(4):764-772.

33. Toth MJ, Miller MS, VanBuren P, et al. Resistance training alters skeletal muscle structure and function in human heart failure: effects at the tissue, cellular and molecular levels. J Physiol. 2012;590(5):1243-1259.

34. Haun CT, Vann CG, Mobley CB, et al. Effects of Graded Whey Supplementation During Extreme-Volume Resistance Training. Front Nutr. 2018;5:84. 
35. DeFreitas JM, Beck TW, Stock MS, Dillon MA, Kasishke PR, 2nd. An examination of the time course of training-induced skeletal muscle hypertrophy. Eur J Appl Physiol. 2011;111(11):2785-2790.

36. Seynnes OR, de Boer M, Narici MV. Early skeletal muscle hypertrophy and architectural changes in response to high-intensity resistance training. J Appl Physiol (1985). 2007;102(1):368-373.

37. Haff G, Triplett NT, National S, Conditioning A. Essentials of strength training and conditioning. 2016.

38. American College of Sports M, Sawka MN, Burke LM, et al. American College of Sports Medicine position stand. Exercise and fluid replacement. Med Sci Sports Exerc. 2007;39(2):377-390.

39. Kephart WC, Wachs TD, Thompson RM, et al. Ten weeks of branched-chain amino acid supplementation improves select performance and immunological variables in trained cyclists. Amino Acids. 2016;48(3):779-789.

40. Fukunaga T, Ichinose Y, Ito M, Kawakami Y, Fukashiro S. Determination of fascicle length and pennation in a contracting human muscle in vivo. J Appl Physiol (1985). 1997;82(1):354-358.

41. Lockwood CM, Roberts MD, Dalbo VJ, et al. Effects of Hydrolyzed Whey versus Other Whey Protein Supplements on the Physiological Response to 8 Weeks of Resistance Exercise in College-Aged Males. J Am Coll Nutr. 2017;36(1):16-27.

42. Lohman M, Tallroth K, Kettunen JA, Marttinen MT. Reproducibility of dual-energy xray absorptiometry total and regional body composition measurements using different scanning positions and definitions of regions. Metabolism. 2009;58(11):1663-1668.

43. Roberson PA, Romero MA, Osburn SC, et al. Skeletal muscle LINE-1 ORF1 mRNA is higher in older humans but decreases with endurance exercise and is negatively associated with higher physical activity. J Appl Physiol (1985). 2019;127(4):895-904.

44. Roberts MD, Romero MA, Mobley CB, et al. Skeletal muscle mitochondrial volume and myozenin-1 protein differences exist between high versus low anabolic responders to resistance training. PeerJ. 2018;6:e5338.

45. Roberts MD, Young KC, Fox CD, et al. An optimized procedure for isolation of rodent and human skeletal muscle sarcoplasmic and myofibrillar proteins. J Biol Methods. 2020;7(1):e127.

46. Cohen S, Brault JJ, Gygi SP, et al. During muscle atrophy, thick, but not thin, filament components are degraded by MuRF1-dependent ubiquitylation. $J$ Cell Biol. 2009;185(6):1083-1095.

47. Dowling P, Zweyer M, Swandulla D, Ohlendieck K. Characterization of Contractile Proteins from Skeletal Muscle Using Gel-Based Top-Down Proteomics. Proteomes. 2019;7(2).

48. Wilkinson DJ, Franchi MV, Brook MS, et al. A validation of the application of $\mathrm{D}(2) \mathrm{O}$ stable isotope tracer techniques for monitoring day-to-day changes in muscle protein subfraction synthesis in humans. Am J Physiol Endocrinol Metab. 2014;306(5):E571579.

49. Bell KE, Brook MS, Snijders T, et al. Integrated Myofibrillar Protein Synthesis in Recovery From Unaccustomed and Accustomed Resistance Exercise With and Without Multi-ingredient Supplementation in Overweight Older Men. Frontiers in nutrition. 2019;6:40-40. 
704 50. Chinkes DL, Rosenblatt J, Wolfe RR. Assessment of the mathematical issues involved in 705 measuring the fractional synthesis rate of protein using the flooding dose technique. Clinical Science. 1993;84(2):177-183. Protein Synthesis Between Endurance-Trai

52. MacDonald AJ, Small AC, Greig CA, et al. A novel oral tracer procedure for measurement of habitual myofibrillar protein synthesis. Rapid Commun Mass Spectrom. 


\section{FIGURE CAPTIONS AND LEGENDS}

\section{Figure 1. Training Volume and Strength Metrics}

Legend: Data are presented as box and whiskers plots including median (central horizontal line),

719 (cross) for training volume load (panel a), unilateral leg press (panel b), unilateral leg extension

720 (panel c), knee extension peak torque at 60\% (panel d), knee extension peak torque at $120 \%$

721 (panel e), knee extension mean torque at $60 \% \mathrm{~s}$ (panel $\mathrm{f}$ ), and knee extension mean torque at

$722120 \%$ s (panel g). Abbreviations: HV. high-volume; HL, high-load. *, indicates a condition $\times$ time

723 interaction whereas POST and POSTPR were greater than PRE.

724

725

726

727

728

729

730

731

732

733

734

735

736

737

738

739

740

741

\section{Figure 2. Segmental Upper Leg Composition}

Legend: Data are presented as box and whiskers plots including median (central horizontal line), $25^{\text {th }}$ and $75^{\text {th }}$ percentile (box), minimum and maximum values (vertical lines) and mean values (cross) for DXA upper leg total mass (panel a), DXA upper lean mass (panel b), and DXA upper leg fat mass (panel c). Abbreviations: HV, high-volume; HL, high-load; DXA, dual energy x-ray absorptiometry.

\section{Figure 3. Vastus Lateralis Muscle Morphology}

Legend: Data are presented as box and whiskers plots including median (central horizontal line), $25^{\text {th }}$ and $75^{\text {th }}$ percentile (box), minimum and maximum values (vertical lines) and mean values (cross) for VL mCSA (panel a), Est. VL fiber length (panel c), VL thickness (panel d), and VL muscle pennation angle (panel f). Representative images: Dual leg MRI for VL mCSA (panel b), ultrasound cross-section for VL thickness (panel e), ultrasound cross-section for pennation 
angle (panel g). No significance was observed following decomposition of condition $\times$ time interaction for VL mCSA. Abbreviations: HV, high-volume; HL, high-load; VL, vastus lateralis;

744 mCSA, muscle cross-sectional area, Est., estimated.

745

746

\section{Figure 4. Muscle Protein Adaptations}

Legend: Data are presented as box and whiskers plots including median (central horizontal line), $25^{\text {th }}$ and $75^{\text {th }}$ percentile (box), minimum and maximum values (vertical lines) and mean values (cross) for sarcoplasmic protein concentrations (panel a), MyHC protein abundance (panel b), actin protein abundance (panel c), tropomyosin protein abundance (panel d), and troponin protein abundance (panel e). Representative image: Coomassie blue stained poly-acrylamide gel for protein abundance. Abbreviations: HV, high-volume; HL, high-load; VL; MyHC, myosin heavy chain; ADU, arbitrary density units; kD, kilodalton.

\section{Figure 5. Six-week Integrated Myofibrillar and Sarcoplasmic Protein Synthetic Rates}

Data are presented as box and whiskers plots including median (central horizontal line), $25^{\text {th }}$ and $75^{\text {th }}$ percentile (box), minimum and maximum values (vertical lines) and mean values (cross) for iMyoPS (panel a) and iSarcoPS (panel b). No significant differences were observed for iMyoPS between conditions. iSarcoPS was significantly lower in the HL condition as compared to the HV condition. Abbreviations: HV, high-volume; HL, high-load; MyoPS, myofibrillar protein synthesis; SarcoPS, sarcoplasmic protein synthesis.

\section{Figure 6. Study Design}


bioRxiv preprint doi: https://doi.org/10.1101/2021.07.01.450728; this version posted July 1, 2021. The copyright holder for this preprint (which was not certified by peer review) is the author/funder, who has granted bioRxiv a license to display the preprint in perpetuity. It is made available under aCC-BY 4.0 International license.

770 Legend: Panel a provides an overview of testing, training, $\mathrm{D}_{2} \mathrm{O}$ administration, and saliva

771 collection times. Panel b provides a schematic of training by day and total training for each

772 week. Abbreviations: wk, week; $\mathrm{D}_{2} \mathrm{O}$, deuterium oxide. 


\section{TABLES}

775 Table 1. Participant characteristics

\begin{tabular}{lr} 
Variable & Mean \pm SD \\
\hline Age (years) & $23 \pm 3$ \\
Height $(\mathrm{cm})$ & $182 \pm 8$ \\
Weight $(\mathrm{kg})$ & $89.5 \pm 11.6$ \\
Lean soft tissue mass $(\mathrm{kg})$ & $69.1 \pm 7.4$ \\
Fat tissue mass $(\mathrm{kg})$ & $17.3 \pm 7.5$ \\
Fat-free mass index & $20.9 \pm 2.2$ \\
Est. 1RM Squat $(\mathrm{kg})$ & $167 \pm 34$ \\
Squat relative to body weight & $1.9 \pm 0.4$
\end{tabular}

$776 \mathrm{~N}=15$ participants. Abbreviations: Est. 1RM, 777 estimated 1 repetition maximum. All measures

778 taken prior to onset of training intervention.

782 Table 2. Body composition changes during training

\begin{tabular}{lrrrc} 
& \multicolumn{1}{c}{ PRE } & \multicolumn{1}{c}{ POST } & \multicolumn{1}{c}{ POSTPR } & \multicolumn{1}{c}{$\begin{array}{c}\text { ANOVA } \\
\text { Variable }\end{array}$} \\
& \multicolumn{1}{c}{ Mean \pm SD } & \multicolumn{1}{c}{ Mean \pm SD } & \multicolumn{1}{c}{ Mean \pm SD } & \multicolumn{1}{c}{ p-value } \\
\hline Total Body Mass $(\mathrm{kg})$ & $69.3 \pm 11.5$ & $90.8 \pm 11.9$ & $90.4 \pm 12.2$ & $\mathbf{< 0 . 0 0 1}^{\dagger}$ \\
DXA Whole Body LSTM $(\mathrm{kg})$ & $69.1 \pm 7.4$ & $70.2 \pm 7.5$ & $69.5 \pm 7.5$ & $\mathbf{0 . 0 0 3}^{*}$ \\
DXA Whole Body Fat Mass $(\mathrm{kg})$ & $17.3 \pm 7.5$ & $17.4 \pm 7.8$ & $17.7 \pm 7.8$ & 0.097
\end{tabular}
measurement was higher at POST than at PRE and POSTPR $(p<0.05)$. 
a

Condition = 0.003 (HL $<\mathrm{HV})$

Time $<0.001$ (all weeks sig.)

$\mathrm{C}^{*} \mathrm{~T}<0.001$

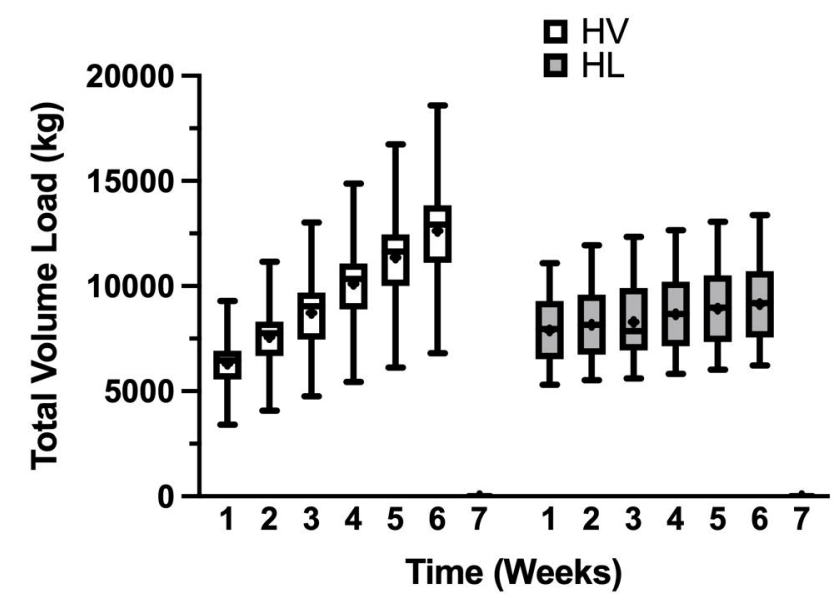

d

Condition $=0.854$

Time $=0.073$

$C^{*} T=0.995$

8.

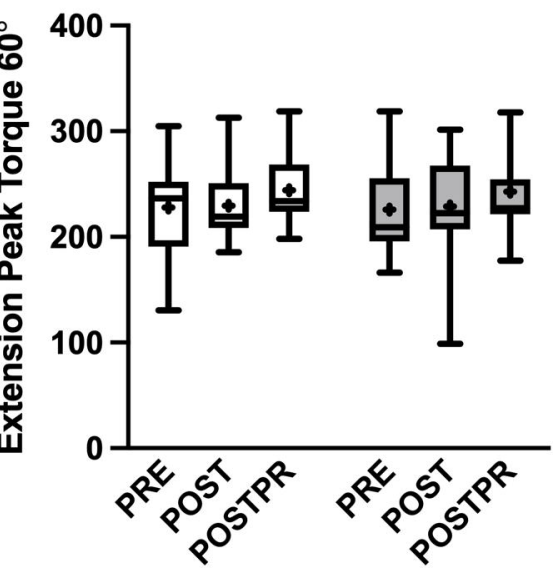

Condition $=0.475$

Time $<0.001$ (PRE<POST\&POSTPR)

$\mathrm{C}^{*} \mathrm{~T}=0.512$

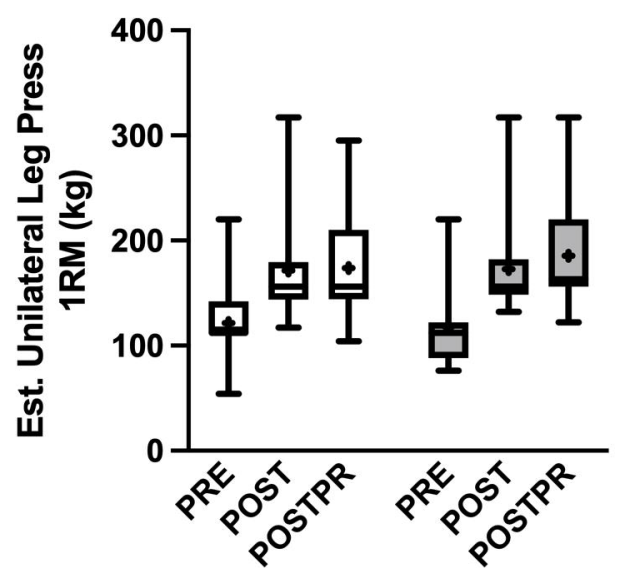

Condition $=0.026(\mathrm{HV}<\mathrm{HL})$

Time $<0.001$ (PRE<POST <POSTPR) $C^{*} \mathrm{~T}=\mathbf{0 . 0 3 2}$

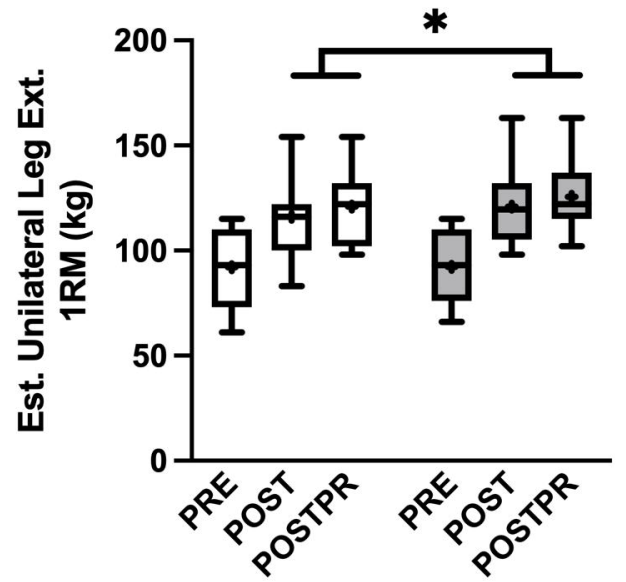

e

Condition $=0.310$

Time $=0.225$

$C^{*} T=0.366$

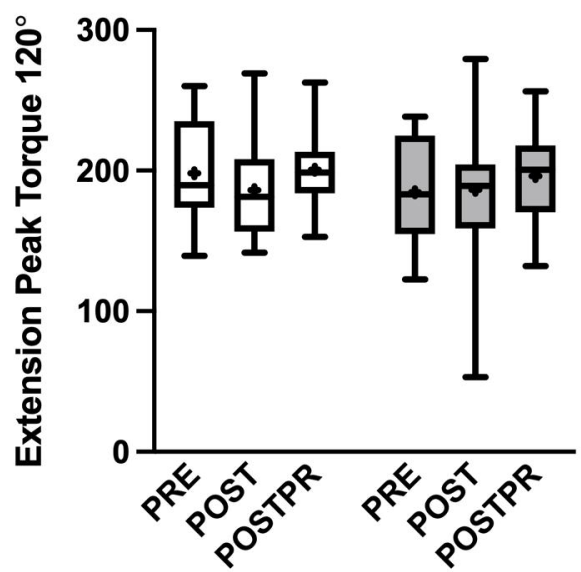

f

Condition $=0.359$

Time $=0.041$ (PRE\&POST<POSTPR) $\mathrm{C}^{\star} \mathrm{T}=0.960$

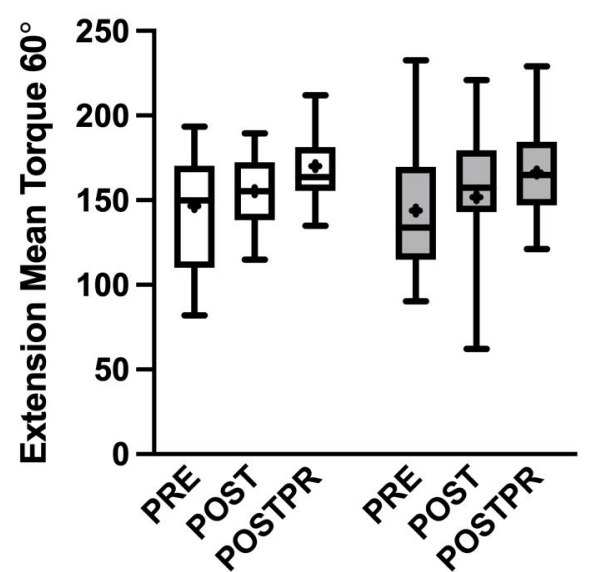

Condition $=0.245$

Time $=0.067$

$\mathrm{C}^{\star} \mathrm{T}=0.681$

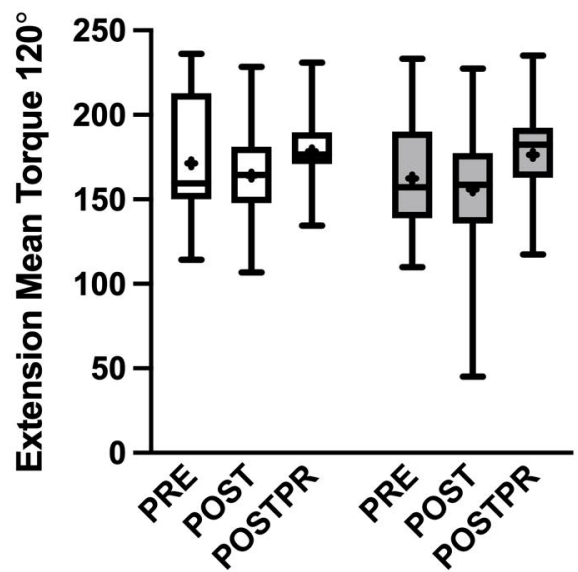


Condition $=0.211$

Time $=0.001$ (PRE<POST\&POSTPR) $C^{*} \mathrm{~T}=0.069$

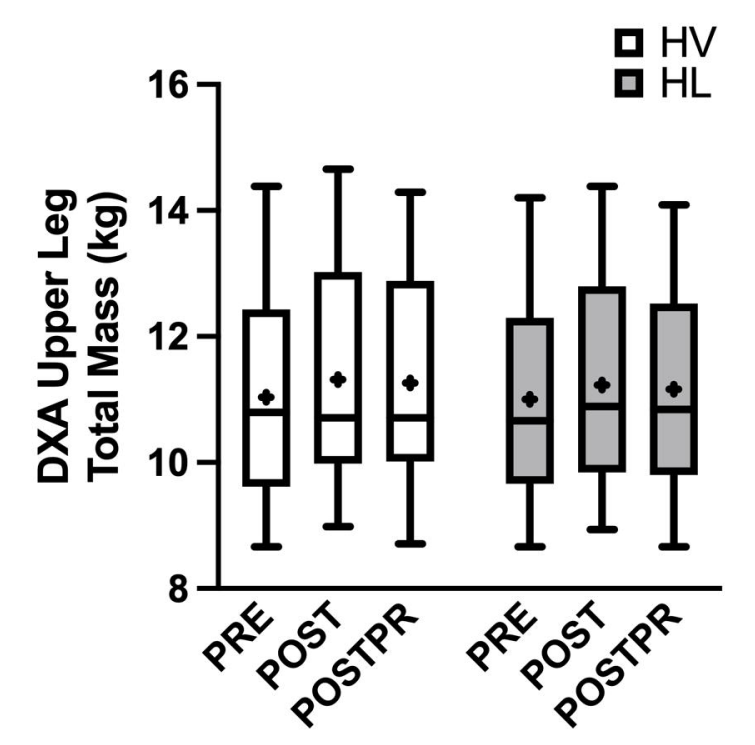

Condition $=0.407$

Time $=0.001$ (PRE<POST\&POSTPR) $C * T=0.174$

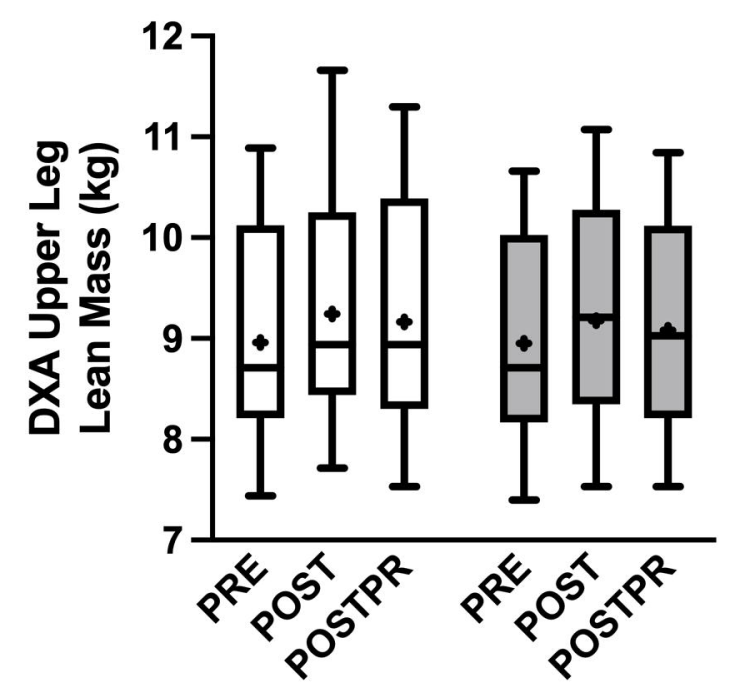

Condition $=0.102$

Time $=0.595$

$C^{\star} \mathrm{T}=0.959$

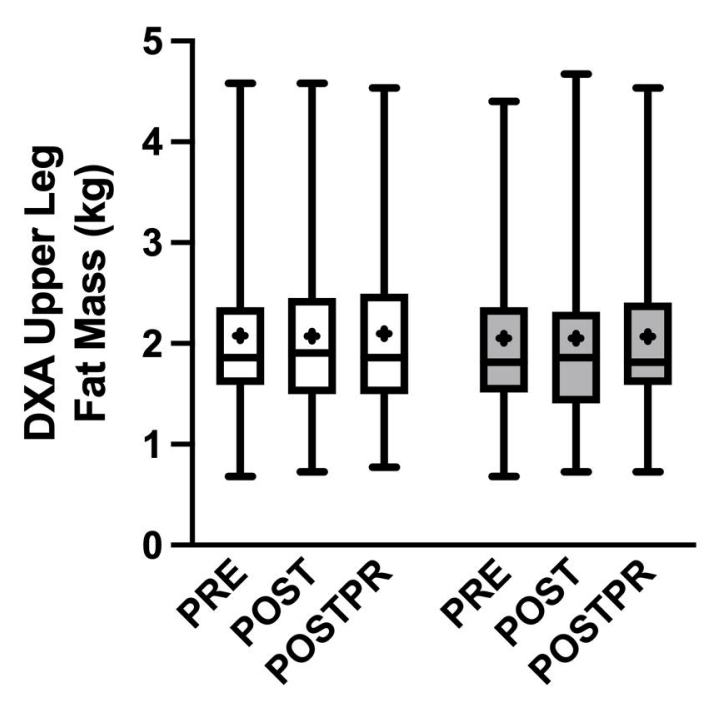


Condition $=0.490$

Time $=0.351$

$C^{*} \mathrm{~T}=\mathbf{0 . 0 4 6}$

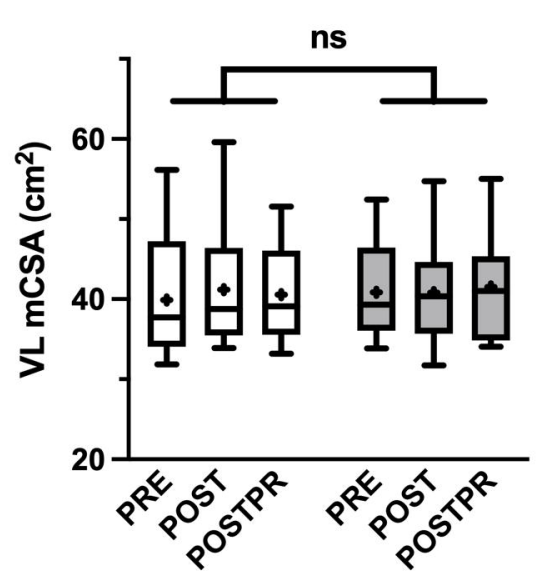

d

Condition $=0.457$

Time $=\mathbf{0 . 0 3 5}$ (PRE\&POSTPR<POST) $C^{*} \mathrm{~T}=0.338$

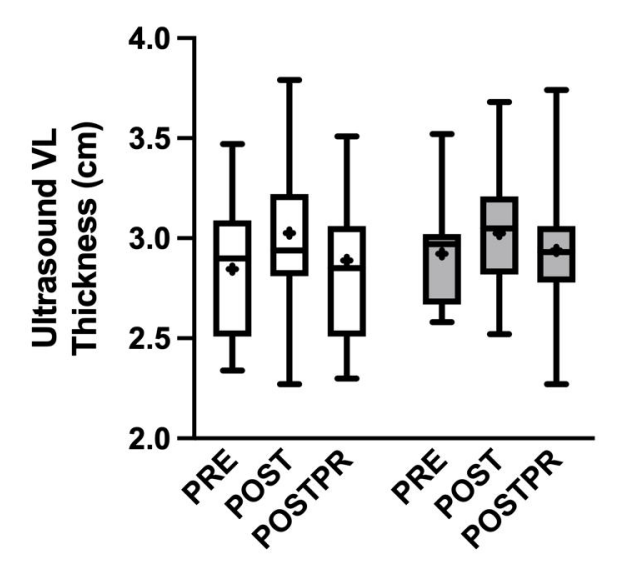

b

C

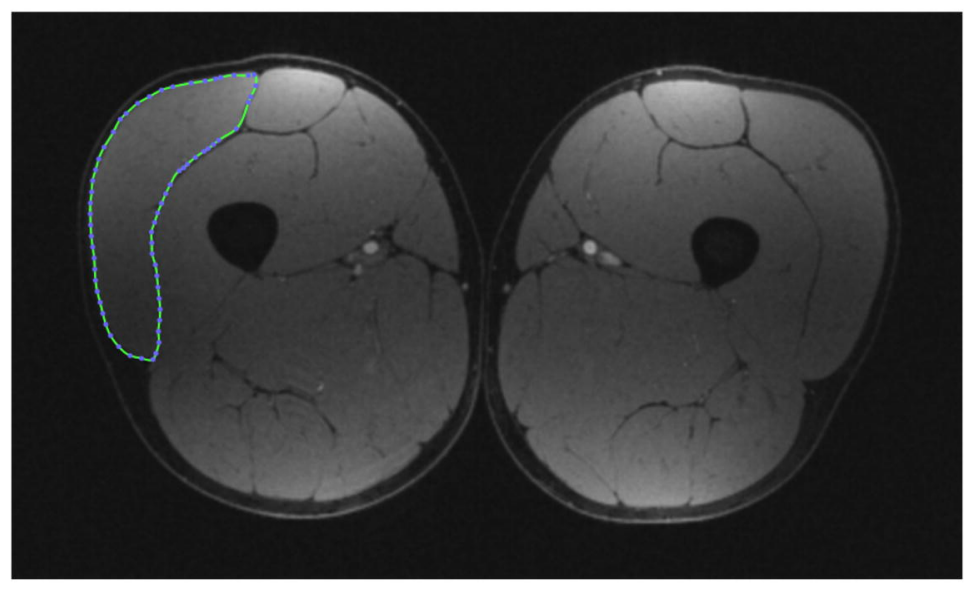

e

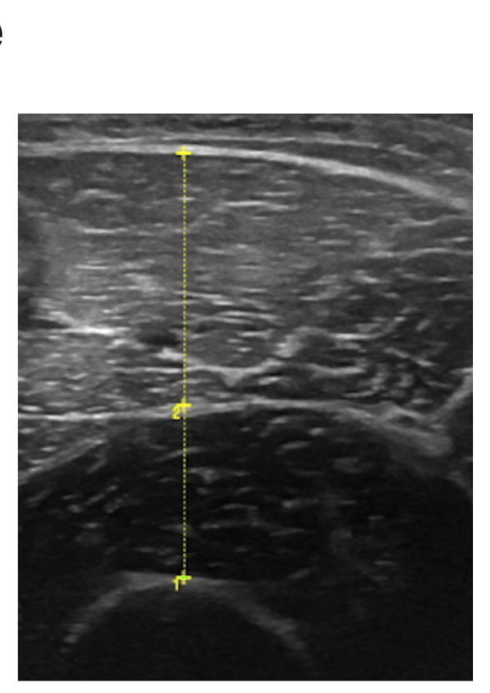

Condition $=0.218$

Time $=0.609$

$C^{*} \mathrm{~T}=0.602$

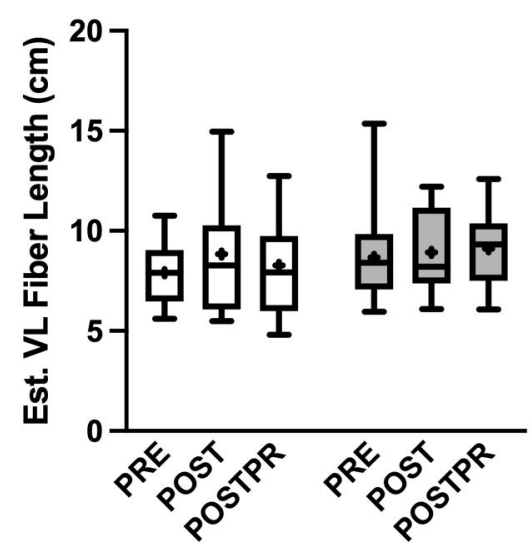

g

Condition $=0.129$

Time $=0.949$

$C^{*} T=0.393$
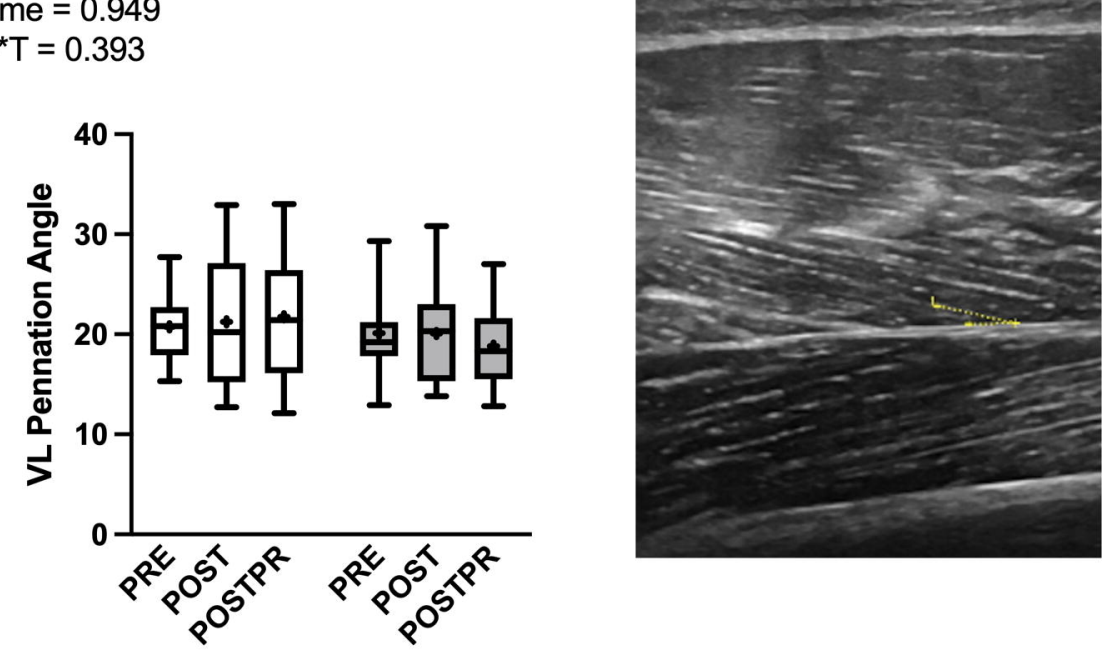


\section{Condition $=0.002(\mathrm{HL}<\mathrm{HV})$}

Time $=0.022$ (POST\&POSTPR<PRE) $C^{\star} \mathrm{T}=0.112$

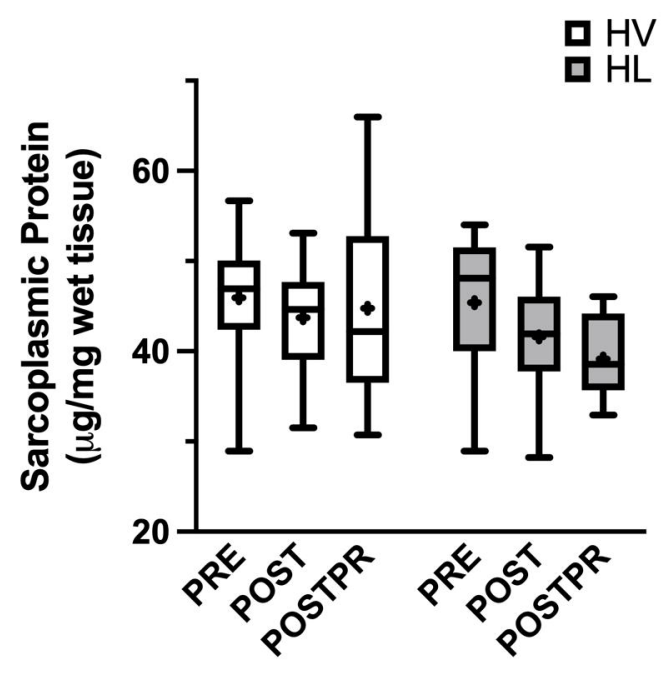

d

Condition $=0.762$

Time $=\mathbf{0 . 0 0 8}$ (POST\&POSTPR<PRE) $\mathrm{C}^{*} \mathrm{~T}=0.180$

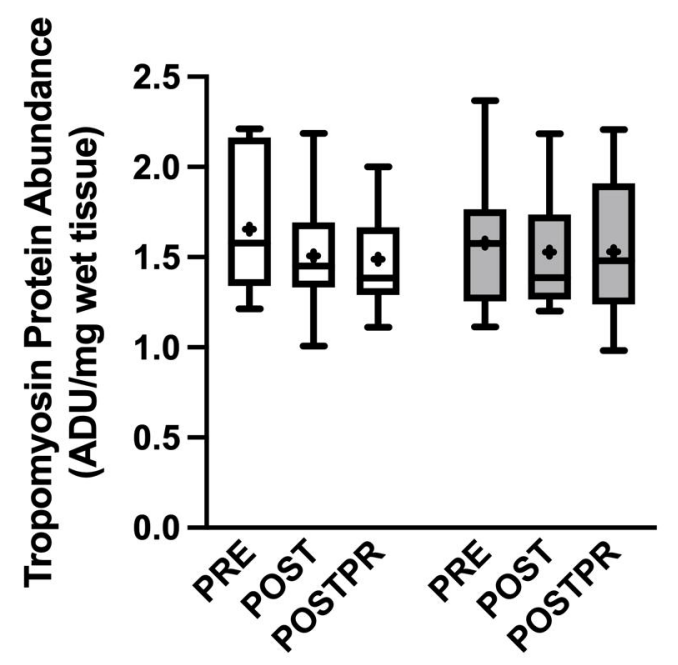

Condition $=0.757$

Time $=0.732$

$C^{\star} \mathrm{T}=0.668$

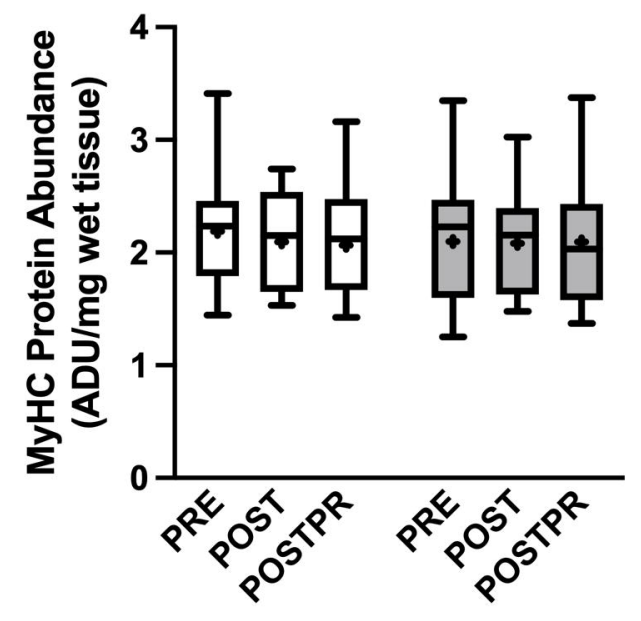

Condition $=0.912$

Time $<0.001$ (POST\&POSTPR $<$ PRE) $C^{*} T=0.112$

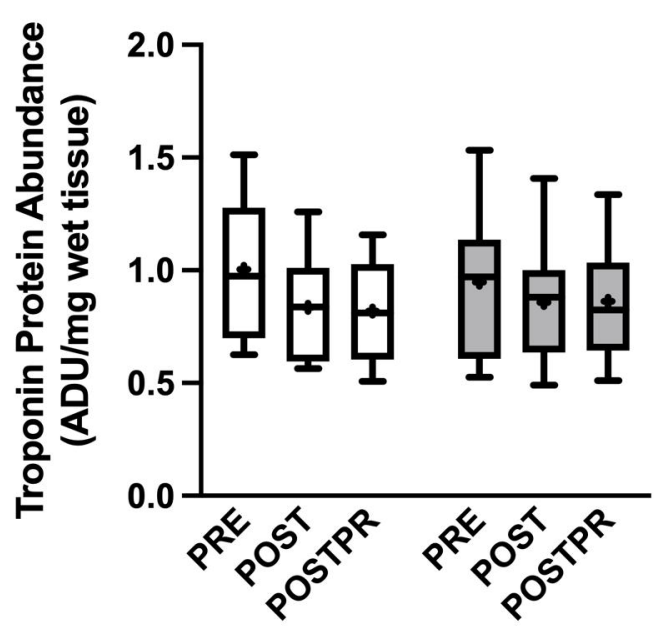

Condition $=0.786$

Time $=0.089$

$C^{*} T=0.254$

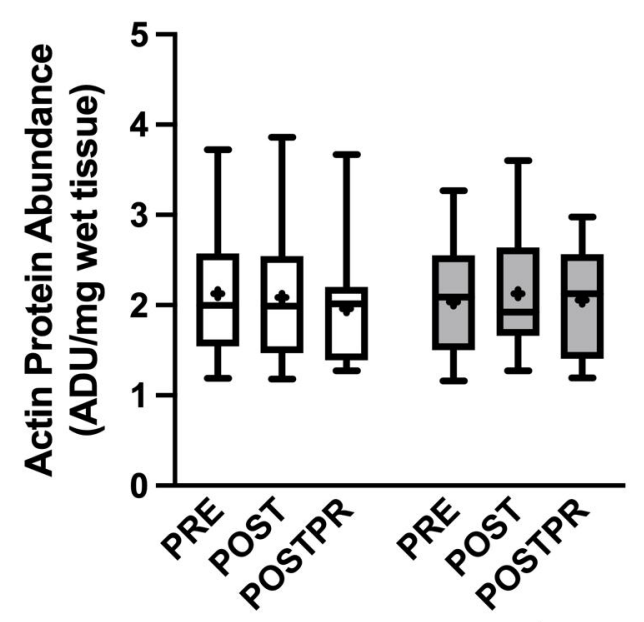

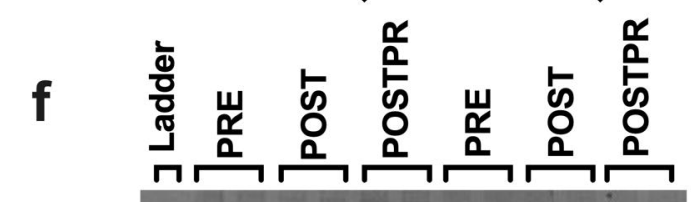

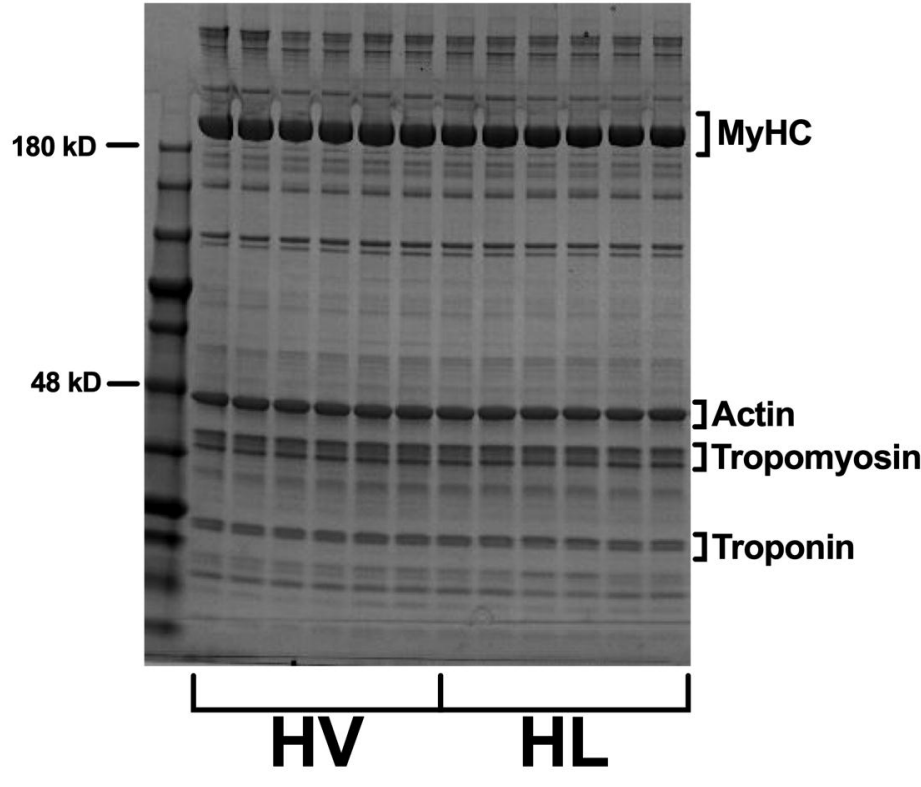



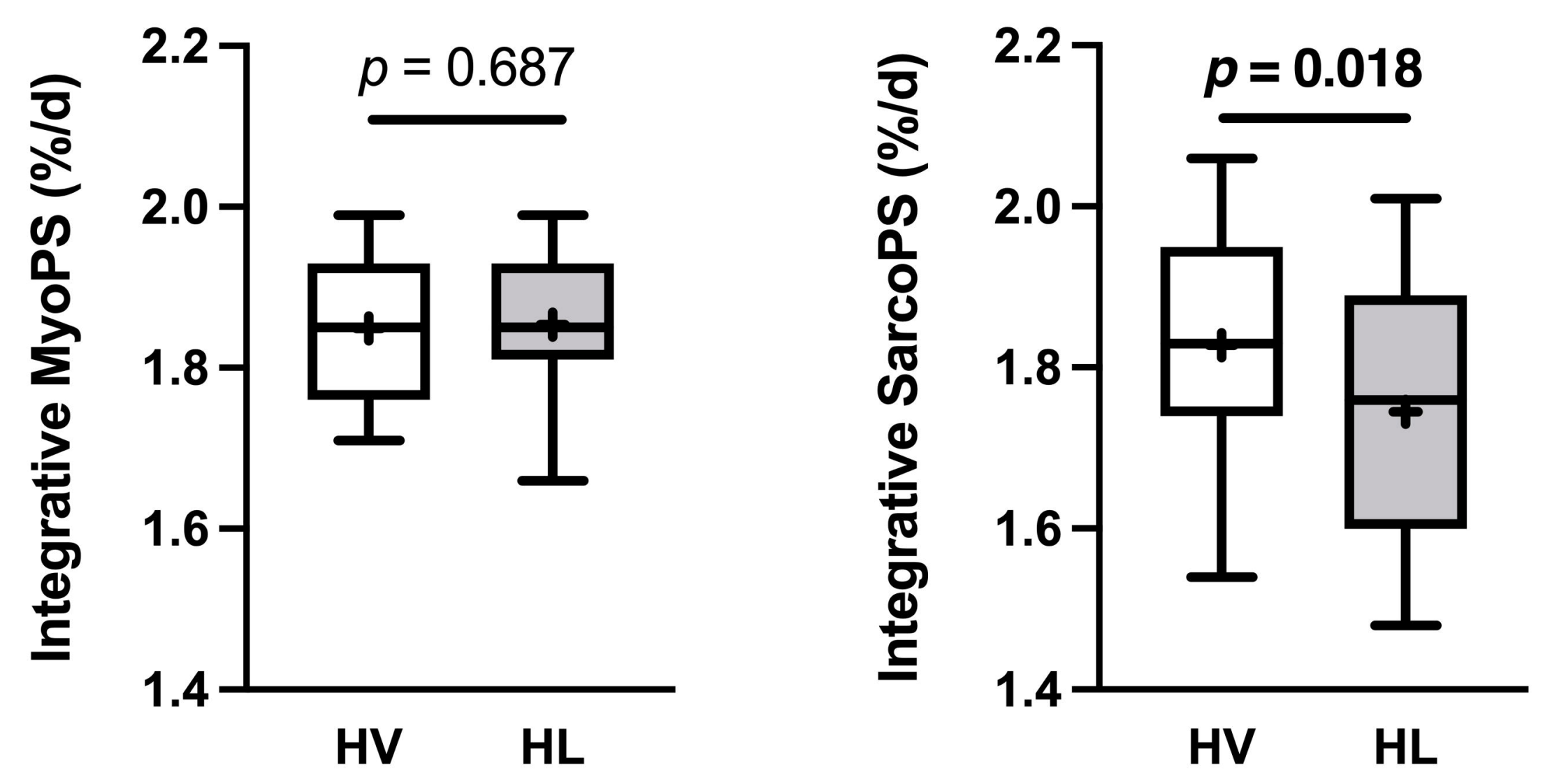


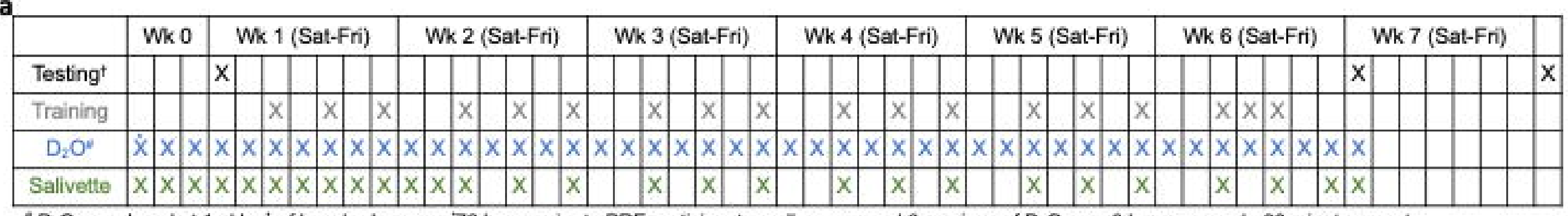

- $\mathrm{D}_{2} \mathrm{O}$ was dosed at $1 \mathrm{~m} \cdot \mathrm{kg}^{-1}$ of lean body mass. 72 hours prior to PRE participants orally consumed 6 servings of $\mathrm{D}_{2} \mathrm{O}$ over 8 hours spaced -90 minutes apart.

t Participants arrived in an orernight fasted state for testing consisting of: USG, height, weight, DXA, US, MRI, blood draw, VL muscle biopsy, lsokinetic dynamometry, strength testing.

\section{b}

Training Protocol"

\begin{tabular}{|c|c|c|c|c|c|c|c|c|c|c|c|}
\hline \multirow[b]{2}{*}{ Wh } & \multirow[b]{2}{*}{ Leg Extensor Exercise } & \multicolumn{5}{|c|}{ High-volume leg } & \multicolumn{5}{|c|}{ High-load leg } \\
\hline & & M & $w$ & $\mathbf{F}$ & Totalhk & $\% 1 \mathrm{RM}$ & $M$ & $w$ & $F$ & Tolal $/ w k$ & $\gamma$ IRM \\
\hline 1 & Unilateral Leg Press \& Unilateral Leg Extension & $2 \times 10$ & $1 \times 10$ & $2 \times 10$ & $5 \times 10$ & $60 \%$ & $3 \times 5$ & $3 \times 5$ & $3 \times 5$ & $9 \times 5$ & $82.5 \%$ \\
\hline 2 & Unilateral Leg Press \& Unilateral Leg Extension & $2 \times 10$ & $2 \times 10$ & $2 \times 10$ & $6 \times 10$ & $60 \%$ & $3 \times 5$ & $3 \times 5$ & $3 \times 5$ & $9 \times 5$ & $85.0 \%$ \\
\hline 3 & Unilateral Leg Press \& Unilateral Leg Extension & $2 \times 10$ & $3 \times 10$ & $2 \times 10$ & $7 \times 10$ & $60 \%$ & $3 \times 5$ & $3 \times 5$ & $3 \times 5$ & $9 \times 5$ & $87.5 \%$ \\
\hline 4 & Unilaleral Leg Press \& Unilaleral Leg Extension & $3 \times 10$ & $2 \times 10$ & $3 \times 10$ & $8 \times 10$ & $60 \%$ & $3 \times 5$ & $3 \times 5$ & $3 \times 5$ & $9 \times 5$ & $90.0 \%$ \\
\hline 5 & Unilateral Leg Press \& Unilateral Leg Extension & $3 \times 10$ & $3 \times 10$ & $3 \times 10$ & $9 \times 10$ & $60 \%$ & $3 \times 5$ & $3 \times 5$ & $3 \times 5$ & $9 \times 5$ & $92.5 \%$ \\
\hline 6 & Unilateral Leg Press \& Unilateral Leg Extension & $3 \times 10$ & $4 \times 10$ & $3 \times 10$ & $10 \times 10$ & $60 \%$ & $3 \times 5$ & $3 \times 5$ & $3 \times 5$ & $9 \times 5$ & $95.0 \%$ \\
\hline 7 & \multicolumn{11}{|c|}{ Cossation of training } \\
\hline
\end{tabular}

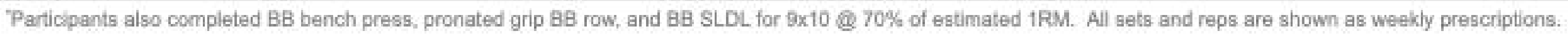

